\title{
Neutron Reflection Study of Surface Adsorption of Fc, Fab, and the Whole mAb
}

DOI:

10.1021/acsami.7b06131

\section{Document Version}

Accepted author manuscript

Link to publication record in Manchester Research Explorer

\section{Citation for published version (APA):}

Li, Z., Li, R., Smith, C., Pan, F., Campana, M., Webster, J. P. R., Van Der Walle, C. F., Uddin, S., Bishop, S. M., Narwal, R., Warwicker, J., \& Lu, J. R. (2017). Neutron Reflection Study of Surface Adsorption of Fc, Fab, and the Whole mAb. ACS Applied Materials and Interfaces, 9(27), 23202-23211. https://doi.org/10.1021/acsami.7b06131

\section{Published in:}

ACS Applied Materials and Interfaces

\section{Citing this paper}

Please note that where the full-text provided on Manchester Research Explorer is the Author Accepted Manuscript or Proof version this may differ from the final Published version. If citing, it is advised that you check and use the publisher's definitive version.

\section{General rights}

Copyright and moral rights for the publications made accessible in the Research Explorer are retained by the authors and/or other copyright owners and it is a condition of accessing publications that users recognise and abide by the legal requirements associated with these rights.

\section{Takedown policy}

If you believe that this document breaches copyright please refer to the University of Manchester's Takedown Procedures [http://man.ac.uk/04Y6Bo] or contact uml.scholarlycommunications@manchester.ac.uk providing relevant details, so we can investigate your claim.

\section{OPEN ACCESS}


To appear in ACS Appl. Mater. Interfaces 2017

DOI: $10.1021 / \mathrm{acsami} .7 \mathrm{~b} 06131$

\section{Neutron reflection study of surface adsorption of Fc, Fab and the whole} mAb

Zongyi Li [1], Ruiheng Li [1], Charles Smith [1], Fang Pan [1], Mario Campana [2], John R P Webster [2], Christopher F van der Walle [3], Shahid Uddin [3], Steve M Bishop [4],

Rojaramani Narwal [4], Jim Warwicker [5], Jian Ren Lu [1]

[1] Biological Physics Laboratory, School of Physics and Astronomy, University of Manchester, Oxford Road, Schuster Building, Manchester M13 9PL, UK.

[2] ISIS Neutron Facility, STFC, Chilton, Didcot OX11 0QZ, UK.

[3] Formulation Sciences, MedImmune Ltd, Sir Aaron Klug Building, Granta Park, Cambridge CB21 6GH, UK

[4] Formulation Sciences, MedImmune LLC, Gaithersburg, MD 20878, USA.

[5] Manchester Institute of Biotechnology, School of Chemistry, University of Manchester, 131 Princess Street, Manchester M1 7DN, UK.

Corresponding author: Jian R Lu (email: j.lu@manchester.ac.uk; tel: +44 161 2003926)

\section{Keywords:}

mAb, surface adsorption, co-adsorption, antibody, structural unfolding, self-assembly, globular stability, neutron reflection 


\begin{abstract}
Characterizing the influence of fragment crystallization $(\mathrm{Fc})$ and antigen-binding fragment (Fab) on monoclonal antibody (mAb) adsorption at the air/water interface is an important step to understanding liquid $\mathrm{mAb}$ drug product stability during manufacture, shipping and storage. Here, neutron reflection is used to study the air/water adsorption of a mAb and its $\mathrm{Fc}$ and Fab fragments. By varying the isotopic contrast, the adsorbed amount, thickness, orientation and immersion of the adsorbed layers could be determined unambiguously. Whilst Fc adsorption reached saturation within the hour, its surface adsorbed amount showed little variation with bulk concentration. In contrast, Fab adsorption was slower and the adsorbed amount was concentration dependent. The much higher Fc adsorption, compared to Fab, was linked to its lower surface charge. Time and concentration dependence of mAb adsorption was dominated by Fab behavior although both Fab and Fc behaviors contributed to the amount of mAb adsorbed. Changing the $\mathrm{pH}$ from 5.5 to 8.8 did not much perturb the adsorbed amount of Fc, Fab or mAb. However, a small decrease in adsorption was observed for the Fc over $\mathrm{pH}$ 8-8.8 and vice versa for the Fab and $\mathrm{mAb}$, consistent with a dominant Fab behavior. As bulk concentration increased from 5 to $50 \mathrm{ppm}$, the thicknesses of the Fc layers were almost constant at $40 \AA$, while Fab and mAb layers increased from $45 \AA$ to $50 \AA$. These results imply that the adsorbed $\mathrm{mAb}, \mathrm{Fc}$ and $\mathrm{Fab}$ all retained their globular structures and were oriented with their short axial lengths perpendicular to the interface.
\end{abstract}




\section{Introduction}

Monoclonal antibody $(\mathrm{mAb})$ therapies are fast becoming effective treatments for many diseases worldwide. ${ }^{1}$ Many therapeutic mAbs are of the IgG1 isotype and (like isotypes IgG2, 3 and 4) comprised of a fragment crystallization (Fc) and two antigen-binding fragments (Fabs). The Fc comprises constant domains $\mathrm{C}_{\mathrm{H}} \gamma 3$ and $\mathrm{C}_{\mathrm{H}} \gamma 2$ for each of the two heavy chains, linked via a hinge to $C_{H} \gamma 1$ and a variable domain $\left(V_{H}\right)$, which together with the light chain $C_{L} \kappa / \lambda$ and $V_{L}$ domains comprise each Fab; Asn297 on $C_{H} \gamma 2$ harbors the biantennary $\mathrm{N}$-glycan comprising a core structure of two $\beta$ - $D$ - $N$-acetylglucosamine (GlcNAc) and three mannose (Man) residues, partially fucosylated as in the predominant G0f: GlcNAc $_{2} \mathrm{Man}_{3} \mathrm{GlcNAc}_{2}$ Fuc. $^{2}$ Like many other protein molecules, mAbs are amphiphilic and capable of adsorbing and desorbing from the air/water interface. ${ }^{3}$ This interfacial behavior is relevant to manufacturing processes where a liquid mAb product may be exposed to air during fill-finish into a container closure system, or during shipping/storage of vials filled with liquid drug product. It is also relevant to the intravenous administration of an $\mathrm{mAb}$ at very low concentrations via a giving set, where significant adsorption to the infusion bag, air/water interface and tubing may result in a lower than desired dose. ${ }^{4,5}$ One could expect to quantify the loss of mAb in this scenario using a facile UV-vis spectroscopy method, though characterizing the nature of the adsorbed layer(s) has proven more complex. Supplementary surface tension measurements (which are well established, relatively straightforward and usefully employed in this field ${ }^{6}$ ) could next be used to generate surface pressure data but these provide little insight to the structural implications for the adsorbed protein. A number of reports on $\mathrm{mAb}$ adsorption at the interface have employed either fluorescently- or nonlabelled protein with spectroscopic and microbalance techniques. ${ }^{7-9}$ Thus, a body of evidence is emerging and is reasonably in agreement with regard to the extent of mAb adsorption at interfaces under various surface and buffer conditions. In addition to quantifying the adsorbed layer, infrared spectroscopy has been used to probe mAb unfolding at the interface. ${ }^{10}$ Similarly, measurement of hydrophobicity of the mAb layer adsorbed at the air/liquid interface via Nile Red fluorescence provides a simple tool to infer the kinetics of adsorption and unfolding. ${ }^{11}$

The adsorption-unfolding-desorption sequence of events is generally regarded to increase the propensity of protein aggregation through partially folded intermediates; a recent report proposing that electrostatic interactions remain dominant. ${ }^{12}$ The relationship between mAb adsorption and the generation of particulates has also been demonstrated through competition 
with increasing polysorbate 20 concentrations, in agitated siliconized syringes. ${ }^{13}$ To more precisely capture the change in alignment, reorientation and conformation of adsorbed protein molecules as a function of surface fraction it is necessary to probe the interface using neutron reflection (NR). ${ }^{14}$ Such detailed data is well established for several surface active proteins encompassing a variety of structural motifs. ${ }^{15,16}$ Thus, it is expected that NR will play an increasingly important role in determining mAb surface active behavior at the level of the individual domains and thereby help mitigate the risk of adsorption induced unfolding and aggregation.

Prior work by our group in this area set out to study mAb adsorption at the air/liquid interface in the presence of polysorbate 80 , which is widely added to mAb drug substances. ${ }^{17}$ Comparing Fc and Fab adsorption under similar conditions will lead to an understanding of how these fragments affect the behavior of the whole mAb. As a first step towards this goal, Fc and Fab domains were obtained by digestion and re-purification of an IgG1 termed ' $\mathrm{COE}$ 3'. The propensity of each domain versus the intact $\mathrm{mAb}$ to undergo reorientation and unfolding at the interface can then be related to the physiochemical properties of the two bulk phases which have a distinct physicochemical nature. Through the NR study, the amount and structural conformation of the adsorbed fragment and antibody layers at the air/water interface can be determined with the help of isotopic contrasts, achieved by varying the ratio of $\mathrm{H}_{2} \mathrm{O}$ and $\mathrm{D}_{2} \mathrm{O}$. We show that adsorbed $\mathrm{mAb}$ is most accurately represented by a uniform layer, indicating no unfolding or leading to the formation of polymer-like distributions along the surface normal direction. However, Fc and Fab behave differently and their respective contributions to the interfacial behavior of the mAb are quite different and explored herein. Because Fc is relatively more hydrophobic, it prefers to project out of the surface of water. This study has demonstrated the power of NR in helping to investigate how the constituent fragments affect the amount and structural conformation of adsorbed mAb molecules.

\section{Materials and experimental methods}

\subsection{Materials}

The mAb used in this study, COE-3, was expressed in Chinese hamster ovary cells and purified using industry-standard methods by MedImmune. Roberts et al. have previously studied its solution behavior under a range of $\mathrm{mAb}$ concentrations. ${ }^{18} \mathrm{COE}-3$ is a full length human IgG1 $\kappa$ with molecular weight equal to $145,560 \mathrm{Da}$ (assuming average glycans), isoelectric point (pI) of 8.44 and extinction coefficient at $280 \mathrm{~nm}$ of $1.43\left(\mathrm{mlmg}^{-1} \mathrm{~cm}^{-1}\right)$. It was supplied as a stock solution of $46.4 \mathrm{mg} / \mathrm{ml}$ in 'His buffer' ( $25 \mathrm{mM}$ histidine/histidine 
hydrochloride, $7 \%$ w/v sucrose $\mathrm{pH}$ 6.0), Batch No: SP12-423. Fc and Fab fractions were produced by papain digestion of COE-3, BN: SP12-423, followed by protein A capture of Fc (Fab flow-through) and ultrafiltration into phosphate buffered saline (PBS), supplied as stock solutions at $55.6 \mathrm{mg} / \mathrm{ml}(\mathrm{BN}$ : SP14-220, $\mathrm{MW}=52,806 \mathrm{Da}, \mathrm{pI}=6.36)$ and 45.0 $\mathrm{mg} / \mathrm{ml}(\mathrm{BN}: \mathrm{SP} 14-219, \mathrm{MW}=47,450 \mathrm{Da}, \mathrm{pI}=9.64)$, respectively. The respective extinction coefficients at $280 \mathrm{~nm}$ were 1.36 for Fc and 1.43 for Fab $\left(\mathrm{mlmg}^{-1} \mathrm{~cm}^{-1}\right)$. Purity of the $\mathrm{Fc}$ and $\mathrm{Fab}$ fractions determined by high-performance size exclusion chromatography was 99.2 and $99.7 \%$, respectively.

The stock samples were stored under $-80{ }^{\circ} \mathrm{C}$ and when needed, each was thawed and diluted directly into histidine buffer at $\mathrm{pH} 5.5$, also at the ionic strength of $25 \mathrm{mM}$. Samples were diluted into subphases of different ratios of $\mathrm{H}_{2} \mathrm{O}$ and $\mathrm{D}_{2} \mathrm{O}$ under the same ionic strength and $\mathrm{pH}$ as specified. Phosphate buffers (sodium salts) were used to prepare buffer solutions at other pHs $(7,8$ and 8.8) studied in this work, again with the total ionic strength fixed at 25 $\mathrm{mM}$. As the concentrations studied in this work were very low, typically below $1 \mathrm{mg} / \mathrm{ml}$ (1000 ppm), sample dilutions into $\mathrm{D}_{2} \mathrm{O}$ introduced very low levels of $\mathrm{H}_{2} \mathrm{O}$, with the exact amount noted and taken into account during neutron data analysis. The translated sequences of the heavy and light chains are given in Table S1 of the Supporting Information, allowing the relevant physical properties such as scattering lengths (SL) and scattering length densities (SLD, $\rho$ ) to be calculated under different solvent isotopic contrasts (Table 1).

$\mathrm{D}_{2} \mathrm{O}(99 \% \mathrm{D})$, histidine and histidine hydrochloride were purchased from Sigma-Aldrich and also used as supplied. $\mathrm{H}_{2} \mathrm{O}$ was processed using an Elgastat PURELAB water purification system. SL and SLD for $\mathrm{H}_{2} \mathrm{O}, \mathrm{D}_{2} \mathrm{O}$ are given in Table $\mathrm{S} 2$ from which any different ratios of them can be calculated.

\subsection{Neutron reflection measurements}

NR measurements were carried out using the SURF reflectometer at ISIS Neutron Facility, Rutherford Appleton Laboratory, STFC, UK. The neutron optical system in SURF provides the neutron wavelength range typically between 0.5 and $6.9 \AA$. With the help of a supermirror setup, neutron reflectivity can be measured at the three incidence angles of 0.35 , 0.8 and $1.5^{\circ}$, covering a momentum transfer range $(\kappa)$ from about 0.01 to $0.5 \AA^{-1}$. The reflectivity from a clean air/ $\mathrm{D}_{2} \mathrm{O}$ surface was first measured as calibration. All the measurements were carried out at the room temperature of $20 \pm 3{ }^{\circ} \mathrm{C}$.

Key structural constants needed for undertaking the model analysis using the above equations are listed in Table 1, with further information about the elementary scattering lengths and 
means to calculate the SLs and SLDs of Fab, Fc and COE-3 under different water contrasts given. SL or SLD varies in response to the exact ratio of $\mathrm{H}_{2} \mathrm{O}$ and $\mathrm{D}_{2} \mathrm{O}$ as shown in Table 1 . This arises from the exchanges of labile $\mathrm{Hs}$ on the amide bond linkages and polar and charged side chains with Ds from the solvent.

Table 1. The scattering length (SL), scattering length density (SLD, $\rho)$, volume (V) and molecular weight (MW) of Fc, Fab and mAb (COE-3) used for the model fitting to neutron reflectivity. The exact sequences for the light and heavy chains in Fab and Fc are given in Table S1.

\begin{tabular}{|c|c|c|c|c|c|}
\hline Component & Contrast & $\mathrm{SL} / 10^{-5} \AA$ & $\mathrm{SLD} / 10^{-6} \AA^{-2}$ & $\mathrm{~V} / ~^{3}$ & $\mathrm{MW}^{3} \mathrm{gmol}^{-1}$ \\
\hline COE-03 & NRW & 35227 & 2.05 & 171740 & 145021 \\
\hline & CM2.58 & 44345 & 2.58 & & 145912 \\
\hline & D2O & 57648 & 3.36 & & 147213 \\
\hline Fc & NRW & 12014 & 2.01 & 59664 & 50033 \\
\hline & CM2.58 & 15022 & 2.52 & & 50326 \\
\hline & D2O & 19403 & 3.25 & & 50753 \\
\hline Fab & NRW & 11607 & 2.07 & 56038 & 47552 \\
\hline & CM2.58 & 14661 & 2.61 & & 47852 \\
\hline & D2O & 19123 & 3.41 & & 48289 \\
\hline
\end{tabular}

\section{Results and discussion}

\subsection{NR measurements and data analysis}

The relationship between the optical geometry of the neutron beam and the surface adsorbed $\mathrm{mAb}$ layer is schematically shown in Figure 1. Neutron reflectivity, $R$, is often plotted as a function of momentum transfer, $\kappa$, perpendicular to the reflecting surface:

$$
\kappa=\frac{4 \pi \sin \theta}{\lambda}
$$

where $\theta$ is the beam incidence angle and $\lambda$ the wavelength. $R$ usually decays fast against $\kappa$ above the critical point. ${ }^{19}$ As often observed in optical systems, interferences also occur in neutron reflection and scattering, with peak positions occurring by following $\kappa=2 n \pi / \tau$ (where $\tau$ denotes film thickness and $n$ is an integer). Hence, the larger the layer thickness the lower $\kappa$ at which interference occurs. 


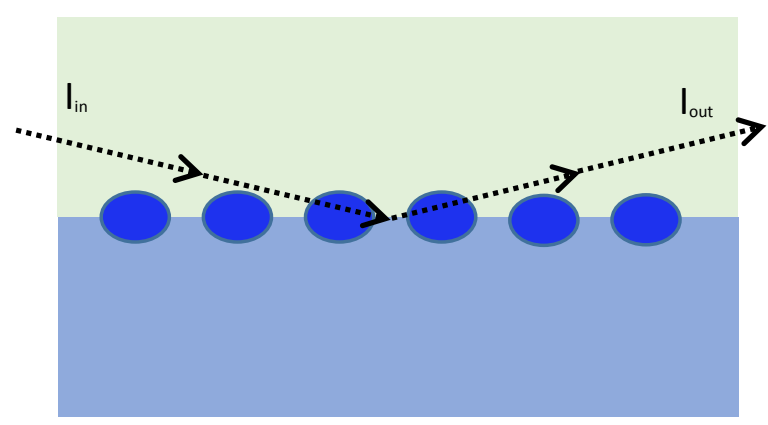

Figure 1. Schematic representation of the optical geometry of neutron beam reflected from the $m A b$ layer adsorbed on the surface of water.

Each $\mathrm{mAb}$ molecule is comprised of an $\mathrm{Fc}$ and $2 \mathrm{Fabs}$, with each of them having the shortest dimensions ranging from 40 to $50 \AA^{20-22}$ Importantly, the surfaces of the Fc and Fab bear different charges and polar groups. Thus, they tend to show amphiphilic characteristics. As discussed above, it is useful to establish how Fc, Fab and mAb molecules adsorb individually. Since these molecules are much larger than typical surfactants and lipids, that have been extensively studied by neutron reflection, the measurable reflectivity tends to fall over the low $\kappa$ range, mostly below $0.1 \AA^{-1}{ }^{24}$
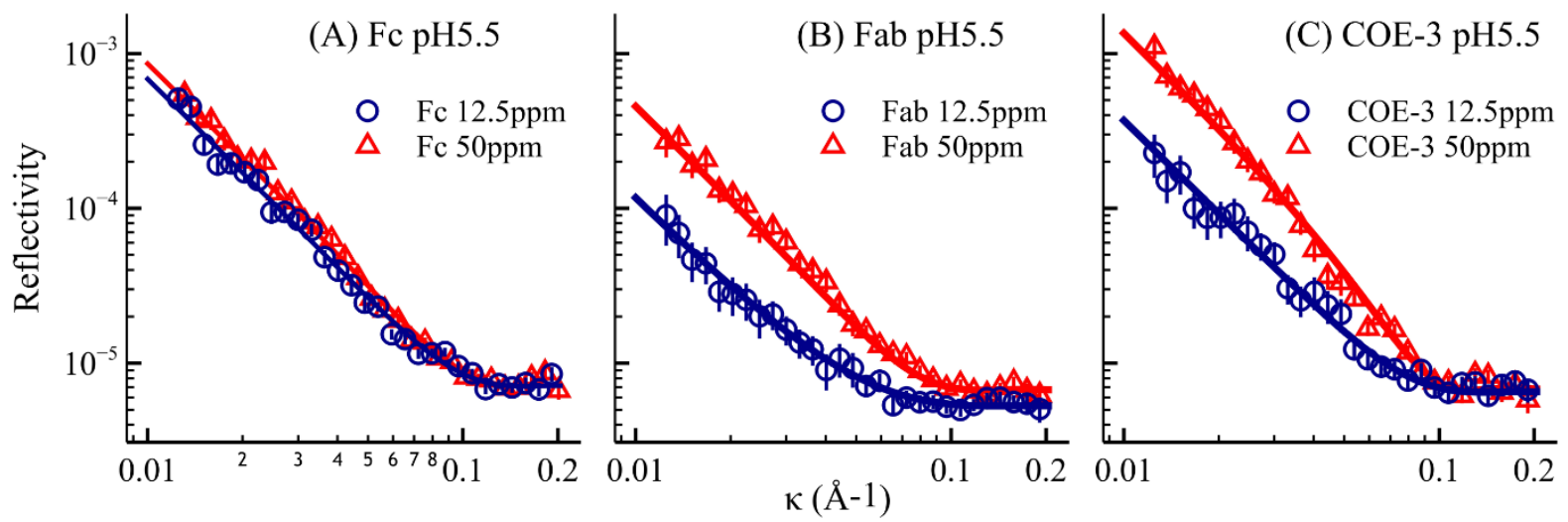

Figure 2. Neutron reflectivity profiles measured from 2 representative concentrations of 12.5 and $50 \mathrm{ppm}$ on the surface of NRW at pH 5.5 (His buffer, ionic strength = $25 \mathrm{mM}$ ): (A) Fc; (B) Fab; (C) $m A b C O E-3$ at $20-22{ }^{\circ} \mathrm{C}$.

One of the main advantages offered by neutron reflection is that hydrogen and deuterium have different scattering lengths and opposite in sign. As a result, the scattering lengths (SL) for $\mathrm{H}_{2} \mathrm{O}$ and $\mathrm{D}_{2} \mathrm{O}$ are also opposite in sign. By mixing $\mathrm{H}_{2} \mathrm{O}$ and $\mathrm{D}_{2} \mathrm{O}$, the scattering length density (SLD) of the aqueous subphase can thus be fine-tuned to cancel out (match) or highlight different parts of the system. As a result, the sensitivity to the interfacially adsorbed layer can be strongly enhanced. When $8.1 \% \mathrm{D}_{2} \mathrm{O}$ and $91.9 \% \mathrm{H}_{2} \mathrm{O}$ (by volume) are mixed, the 
SLD for the water mixture is zero. This mixed water is termed null reflecting water (NRW) as at the air/NRW interface no specular reflection occurs. Upon adsorption of mAbs or their fragments at this interface, specular reflection arises entirely from the adsorbed layer. Hence, the specular reflectivity only contains information about the adsorbed mAb layer in NRW, providing an accurate determination of the adsorbed amount and layer thickness. ${ }^{25}$

Figure 2A shows the exemplar reflectivity profiles measured at 12.5 and $50 \mathrm{ppm}$ (12.5 and 50 $\mu \mathrm{g} / \mathrm{ml}$ ) of Fc under $\mathrm{pH} 5.5$ from the surface of NRW. The difference between the reflectivity profiles is very small, showing that an increase in bulk Fc concentration is only associated to a small increase in adsorbed amount. To avoid the possible time dependent effect, these reflectivity profiles were measured 3-5 hr after the surfaces were equilibrated.

The reflectivity profiles were analyzed using Motofit ${ }^{26}$ and the algorithm was based on the optical matrix formalism as described by Born and Wolf. ${ }^{27}$ The fitting process started with the simulation of an interfacial model from which the reflectivity was calculated. The calculated reflectivity was then compared with the measured one and the process was iterated until the best fit was obtained from the $\chi^{2}$ values from the fitting and visual assessment. The adsorbed layer may need to be divided into a series of sublayers to account for the structural changes along the surface normal direction and each of the sublayers is described by thickness $\left(\tau_{i}\right)$, scattering length density $\left(\rho_{i}\right)$ and roughness, where appropriate. A uniform layer model is often the easiest starting point for protein adsorption, where the volume fraction $\left(\phi_{p}\right)$ in the layer can be expressed as:

$$
\phi_{p}=\frac{\rho}{\rho_{p}}
$$

where $\rho$ and $\rho_{p}$ are the SLDs of the protein layer. The area per protein molecule $\left(A_{p}\right)$ can be obtained using:

$$
A_{p}=\frac{V_{p}}{\tau_{p} \phi_{p}}
$$

where $V_{p}$ is the volume of the protein and $\tau_{p}$ is the thickness obtained from the fit (in $\AA$ ). The surface adsorbed amount or surface concentration $\left(\Gamma_{p}\right.$, measured in $\left.\mathrm{mg} / \mathrm{m}^{2}\right)$ can be expressed as

$$
\Gamma_{p}=\frac{M W}{6.023 A_{p}}
$$

where MW is the protein molecular weight (in $\mathrm{g} / \mathrm{mol}$ ) and $A_{p}$ is in $\AA^{25}$

Using the above approach, the best fits, shown as continuous lines through the measured reflectivity profiles in Figure 2A, led to $\Gamma_{p}=1.3$ and $1.7 \mathrm{mg} / \mathrm{m}^{2}$ from the Fc adsorption at the two concentrations, with thickness constant at around $40 \pm 2 \AA$. For comparison, Figure $2 \mathrm{~B}$ 
shows the two reflectivity profiles measured from Fab adsorption under the same concentrations. The two reflectivity profiles differ both in their intensity and slope in this case, showing very different adsorbed amount and layer thickness. The best uniform layer fits led to $\Gamma_{p}=0.5$ and $1.1 \mathrm{mg} / \mathrm{m}^{2}$ from Fab adsorption at the two concentrations, with thicknesses at $45 \pm 2$ and $50 \pm 2 \AA$, respectively. Unlike Fc, Fab adsorption is clearly concentration-dependent.

Figure 2C shows the two reflectivity profiles measured for the mAb under the same concentrations. Like Fab adsorption, the two reflectivity profiles differ both in intensity and slope, showing the clear effect of mAb concentration. The best uniform layer fits revealed that $\Gamma_{p}=1.0$ and $2.0 \mathrm{mg} / \mathrm{m}^{2}$ at the two concentrations, with thicknesses at 45 and $50 \pm 2 \AA$, respectively. Thus, whilst changes in concentration affect layer thickness and the adsorbed amount in a manner similar to the Fab adsorption, the actual mass of mAb adsorbed almost doubled.

\subsection{Time and concentration dependent adsorption}

From the reflectivity analysis approach as described above, the time-dependent adsorption processes were also examined, with the results shown in Figure 3A for Fc, Figure 3B for Fab and Figure $3 \mathrm{C}$ for $\mathrm{mAb}$. As each reflectivity measurement requires a minimum of 40-60 min to achieve the statistically acceptable quality, any dynamic process faster than $1 \mathrm{hr}$ would not be resolvable. It can be seen from Figure 3A that Fc can adsorb fast and tends to equilibrate within the first 1-2 $\mathrm{hr}$ as the adsorbed amount increases very slightly after this period. In contrast, Fab adsorption is clearly slower and the dynamic process occurs over the period of several hr. Over the low concentration range below $12.5 \mathrm{ppm}$, the dynamic process lasted over $10 \mathrm{hr}$. Over the intermediate concentration range of $25-50 \mathrm{ppm}$ studied, the timedependent adsorption occurred over the first 6-8 hr. At the highest concentration of $100 \mathrm{ppm}$ studied, it reached equilibration after the first 2-3 hr. The main feature of the dynamic adsorption for $\mathrm{mAb}$ (Figure 3C) is broadly similar to that as described from Fab adsorption, that is, the adsorption tended to equilibrate faster with higher concentration, showing the dominant influence of the two Fabs to the behavior of the mAb. 


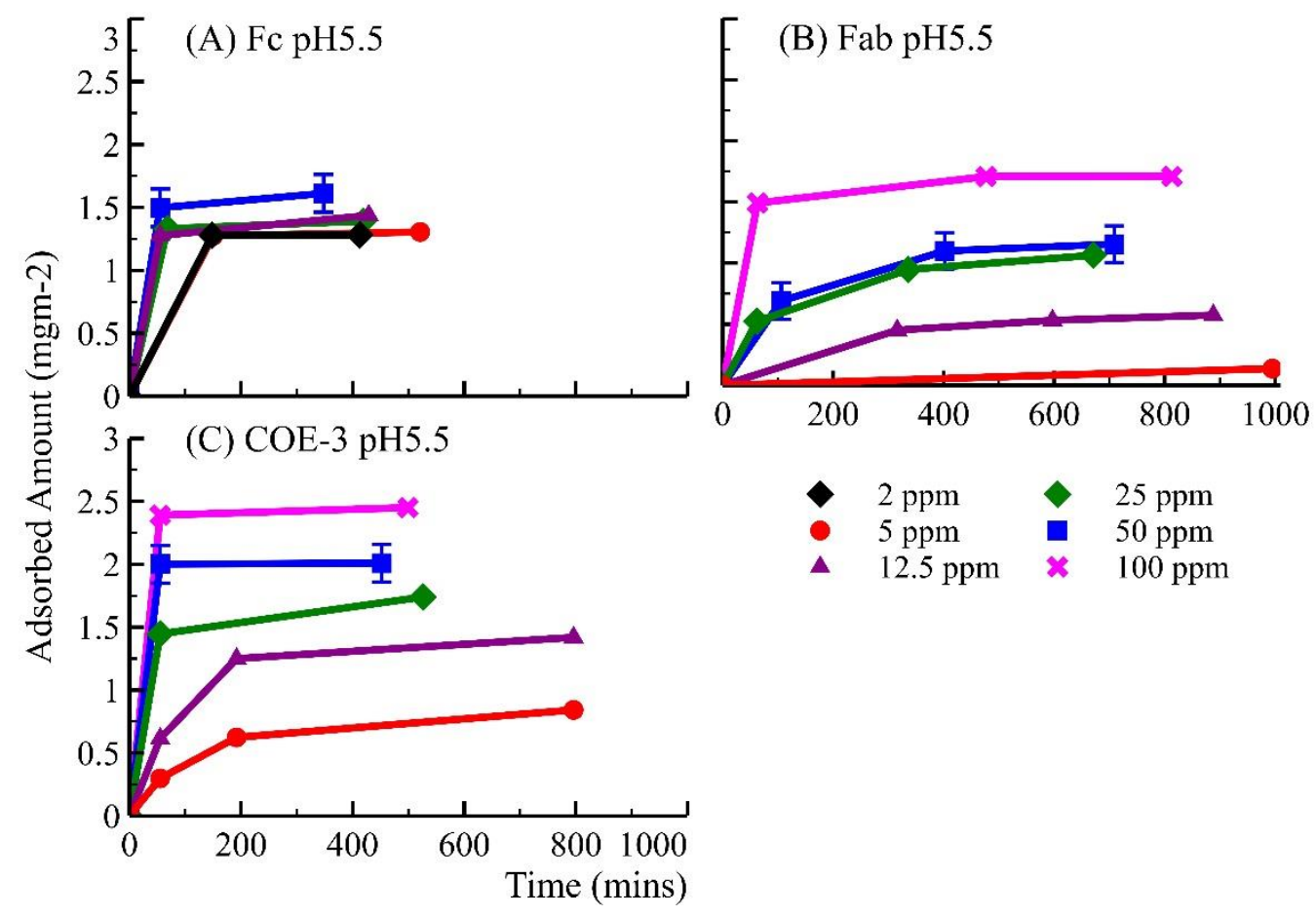

Figure 3. Adsorbed amount plotted against time measured at concentrations ranging from 2 to $100 \mathrm{ppm}$ with the solution $\mathrm{pH}$ fixed at 5.5: (A) Fc; (B) Fab; (C) $\mathrm{mAb} C \mathrm{COE}-3$.

The concentration-dependent adsorption is summarized in Figure 4, where the adsorbed amount was taken from the last points of the time-dependent data sets as shown in Figures 3A, 3B and 3C. Over the concentration range studied (below $100 \mathrm{ppm}$ ), the mass adsorbed from Fc (Figure 4A) is clearly higher than that obtained from Fab, but the Fc adsorbed amount shows a reluctant increase with increasing bulk concentration whilst that of the Fab shows a fast increase. This rate of concentration-dependent increase is clearly inherited by the $\mathrm{mAb}$ and more interestingly, the amount of mAb adsorbed is also influenced by Fc: its adsorbed amount is greater than that of Fab but lower than that of Fc. However, the rate of concentration-dependent rise is similar to that of Fab. This leads the mass adsorbed amount for $\mathrm{mAb}$ to cross that of $\mathrm{Fc}$ at $15 \mathrm{ppm}$. Above this concentration, the mAb displays an adsorption above $\mathrm{Fc}$ and $\mathrm{Fab}$. This means that the mAb combines the different features of its fragments to reach a newly balanced amphiphilicity that bears the distinct influences from its constituent fragments. 

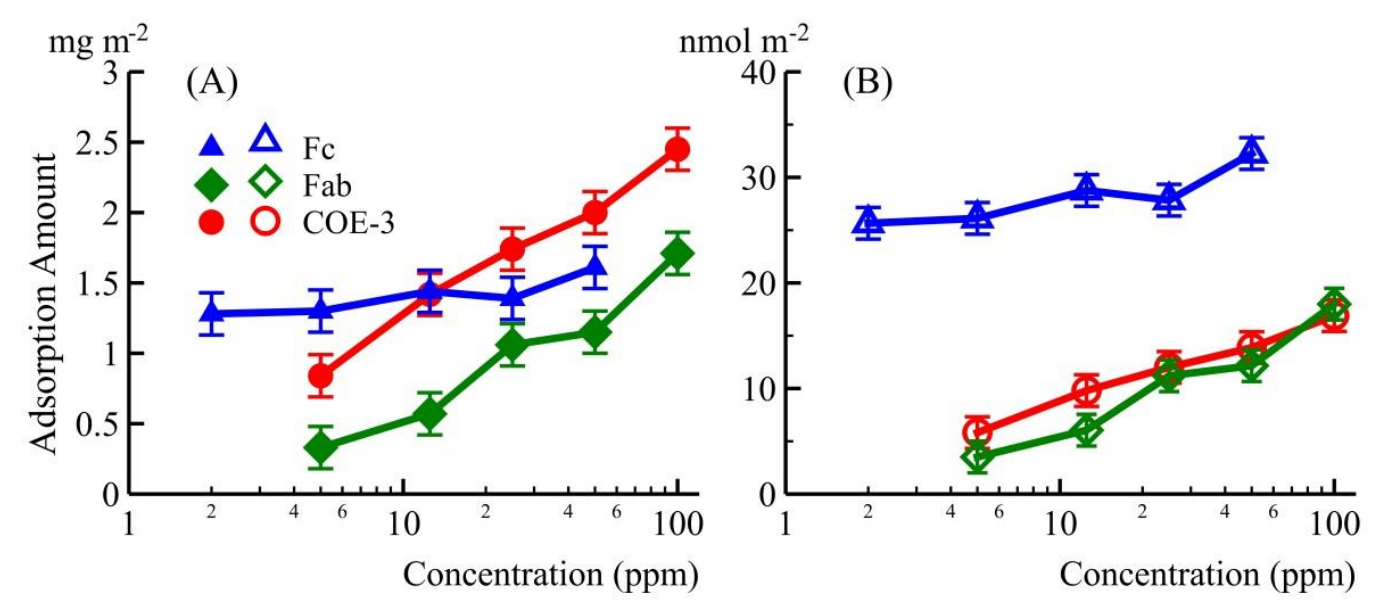

Figure 4. The equilibrated amount of adsorption in $\mathrm{mg} / \mathrm{m}^{2}$ (A) and $\mathrm{nmol} / \mathrm{m}^{2}$ (B) taken from the last point of each set of measurements in Figure 3 plotted against concentration for $F c$ $(\mathbf{\Delta}), \mathrm{Fab}(\bullet)$ and the whole $\mathrm{mAb} C \mathrm{COE}-3(\bullet)$.

Figure $4 \mathrm{~B}$ shows that when the adsorbed amount is presented in $\mathrm{nmol} / \mathrm{m}^{2}$, the $\mathrm{Fab}$ and the mAb have almost identical adsorption curves against bulk concentration whilst the molar adsorbed amount of $\mathrm{Fc}$ is 2-3 times greater, again showing that $\mathrm{Fc}$ is significantly more hydrophobic.

\subsection{Effect of solution $\mathrm{pH}$}

The results as shown above were measured at $\mathrm{pH}$ 5.5. As the isoelectric points for Fc, Fab and mAb vary between $\mathrm{pH} 7$ and 10 (Figure S1), pH shift affects their charges differently. To examine how surface adsorption is affected by solution $\mathrm{pH}$, changes in adsorbed amount were also examined at several other $\mathrm{pH}$ values up to 8.8. The time-dependent change of the adsorbed mass of $\mathrm{Fc}$ is shown in Figure 5A, that for Fab in Figure 5B and that for $\mathrm{mAb}$ in Figure 5C. It can be seen from Figure 5 that whilst $\mathrm{Fc}$ adsorption tends to equilibrate within the first 2-3 hr Fab adsorption shows a steady rise with time, even after the first $10 \mathrm{hr}$. In contrast, mAb adsorption again bears features from the constituent fragments. At $\mathrm{pH} 5.5$, there is no apparent time effect after the first $1 \mathrm{hr}$. The time-dependent adsorption becomes slightly more pronounced at $\mathrm{pH} 7$ and 8 but the dynamic process becomes rather less obvious again at $\mathrm{pH}$ 8.8. Taken together, these time-dependent variations are clearly less significant than what occurs in Fab adsorption but more substantial than the dynamic changes observed from Fc adsorption. 


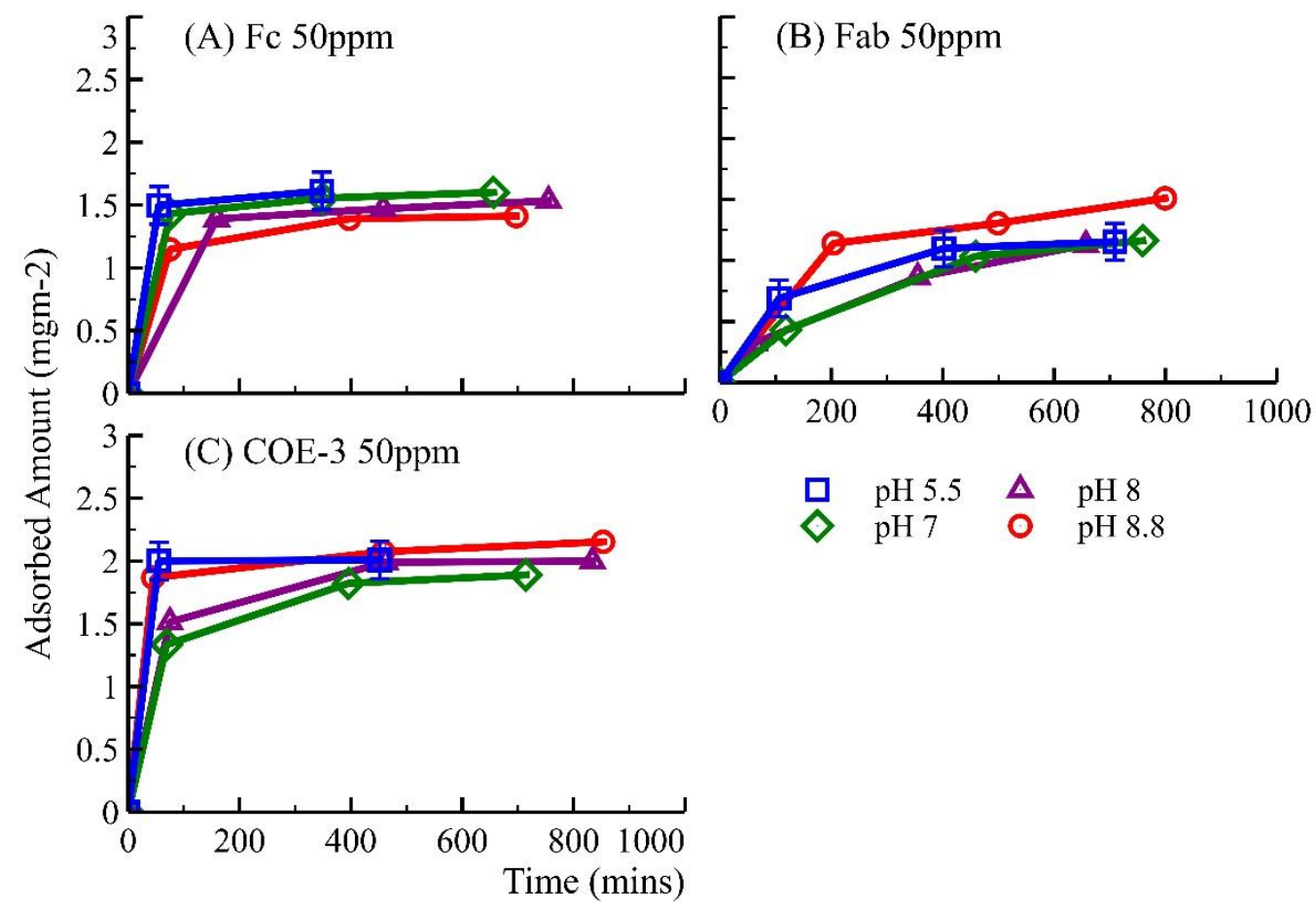

Figure 5. Adsorbed amount plotted against time measured at pH 5.5, 7, 8 and 8.8 with the concentration fixed at $50 \mathrm{ppm}$ : (A) Fc; (B) Fab; (C) mAb COE-3.

Figure $6 \mathrm{~A}$ shows the equilibrium adsorbed mass for $\mathrm{Fc}, \mathrm{Fab}$ and $\mathrm{mAb}$ again by taking the last adsorbed amount measured at each time-dependent $\mathrm{pH}$ change in Figures 5A, 5B and 5C. It can be seen from Figure 6A that the equilibrium adsorbed mass from $\mathrm{Fc}$ is greater than that of Fab whereas that of the mAb is the highest under the fixed concentration of $50 \mathrm{ppm}$. From pH 5.5 to 8, the trend of $\mathrm{pH}$-dependent change is small. From $\mathrm{pH} 8$ to 8.8 , Fc shows a trend of decrease in adsorption whilst Fab shows a rather sharp increase. The exact mechanistic process is unclear but the trend for the $\mathrm{mAb}$ is again more influenced by Fab adsorption, possibly because of the presence of 2 Fabs in each $\mathrm{mAb}$. The $\mathrm{pH}$ dependent process together with the highest mass adsorption from the mAb shows the balanced amphiphilicity arising from both Fc and Fab segments.

When plotted in terms of $\mathrm{nmol} / \mathrm{m}^{2}$ for surface adsorption (Figure $6 \mathrm{~B}$ ), Fc shows the highest adsorption whilst the adsorbed amount for $\mathrm{Fab}$ and $\mathrm{mAb}$ is almost identical. In spite of changes in the relative orders of the adsorbed amount when plotted in mass and molar surface concentration, the $\mathrm{pH}$ effects remain the same. 

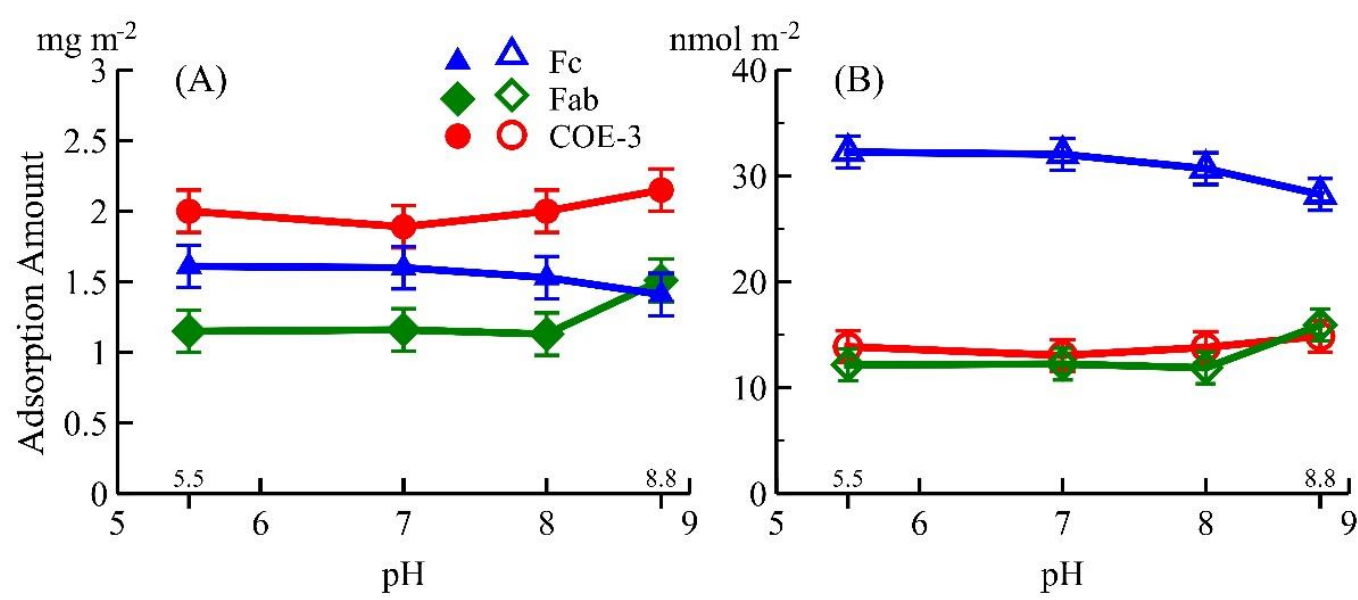

Figure 6. Equilibrated amount of adsorption measured in $\mathrm{mg} / \mathrm{m}^{2}$ (A) and nmol/ $\mathrm{m}^{2}$ (B), taken from the last point of each set of measurements from Figure 5 plotted against $\mathrm{pH}$ for $\mathrm{Fc}_{\mathrm{C}}(\mathbf{\Delta})$, $\mathrm{Fab}(\bullet)$ and $m A b \mathrm{COE}-3(\bullet)$.

\subsection{Changes in layer thickness and extent of immersion in water}

Figure 7 shows the thicknesses measured from equilibrated layers adsorbed under representative concentrations of $\mathrm{Fc}, \mathrm{Fab}$ and $\mathrm{mAb}$, at $\mathrm{pH}$ 5.5. The results clearly show very small changes in layer thickness despite large $\mathrm{Fc}, \mathrm{Fab}$ and $\mathrm{mAb}$ concentration variations. Under the conditions studied, the adsorbed Fc layers remained constant at $40 \pm 2 \AA$ whilst the thicknesses of $\mathrm{Fab}$ and $\mathrm{mAb}$ layers were $45 \AA$ at 5 and $12.5 \mathrm{ppm}$, then slightly increasing to $50 \AA$ at the two high concentrations of 25 and $50 \mathrm{ppm}$. This suggests possible adjustment of structural conformations in response to the increase of surface packing density with bulk solution concentration.

Table S1 shows the translated sequences of heavy and light chains of COE-3. Sequence alignment as shown in Table S3 reveals the complete identity between the COE-3 Fc and the Fc reported for a human IgG1 in the Protein Data Bank (PDB ID 1HZH) ${ }^{20}$ and $96 \%$ similarity to another human Fc (PDB ID 1H3T). ${ }^{21}$ In contrast, alignment of the COE-3 Fab sequence with that of the $1 \mathrm{HZH}$ Fab as shown In Table S4 reveals $74.5 \%$ similarity $^{20}$ and with that of another Fab reported by Tamada et al. with PDB ID 3X3G revealed 55\% similarity only; ${ }^{22}$ the differences reflect the nature of the variable $\left(\mathrm{V}_{\mathrm{H}} / \mathrm{V}_{\mathrm{L}}\right)$ domains which are nevertheless folded consistently in the IgG superfamily. Figure S2 depicts the projections of the crystalline structure of Fc. It is approximately in a doughnut shape, with the outer diameter of $70 \AA$ and height of $40 \AA$. In contrast, Figure S3 depicts the projections of the crystalline structure of Fab. It is approximately in a disc shape but still has a large 'dent' in the center, with the outer diameter of $80 \AA$ and height of $45 \AA$. Figure S4 illustrates the projections of the whole mAb in which the fragments are packed with their short axial lengths aligned perpendicular to the 
substrate surface, resulting in a height of $c a 45 \AA$ and a width of $c a 100 \AA$. The thicknesses measured from NR are close to the short dimensions of $\mathrm{Fab}$ and $\mathrm{Fc},{ }^{20-23}$ suggesting that both Fab and Fc retain their globular structures, and that they do not suffer from any measurable deformation either. An increase in bulk concentration led to increased surface packing density but the Fc layers did not show any measurable change in thickness, although the Fab layers did increase from 45 to $50 \AA$ arising from possible adjustment in structural conformation. Figure S2 shows that the charges on Fc are rather uniformly distributed. It can however be seen from Figure S3 that the surface viewed from the 'left side' bears distinctly more charged groups than that from the 'right side'. The presence of unevenly balanced charge distributions could help the tilting of the Fab once the surface is sufficiently packed. The tilting of surface adsorbed lysozyme molecules has been previously observed by NR studies. ${ }^{28}$ Its transition of surface conformational orientations with rising packing density is also thought to be affected by the uneven charge distribution on the molecular surface.

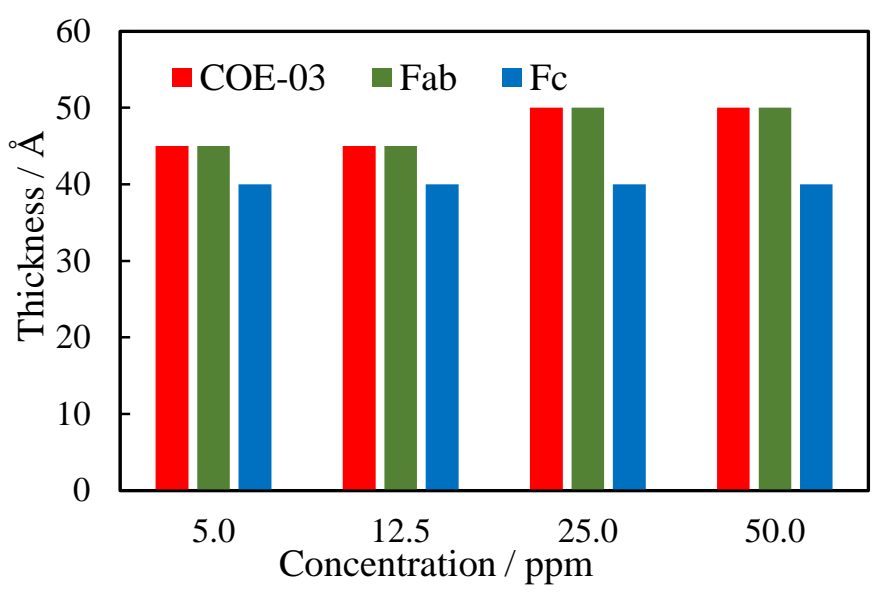

Figure 7. Changes in layer thickness under the equilibrated adsorption taken from the last point of each set of concentration dependent adsorption measurements as shown in Figure 2, plotted against the concentration of Fc (blue), Fab (green) and $\mathrm{mAb} C O E-3$ (red) at pH 5.5 .

In the case of the mAb, similar thicknesses to those of the Fab layers were observed. This implies that Fab and Fc are well aligned in the monolayer and that there is no stacking below or above each other. In contrast, bovine serum albumin (BSA) is a rod-shaped molecule that is loosely linked from 3 consecutive main domains. NR revealed the formation of layers of about $30 \AA$ thick, close to its short axial length and indicative of the sideways-on adsorption. ${ }^{29}$ Increase in bulk concentration could lead to thickness increase to some $40 \AA$ before a sublayer was formed under the main surface layer. Such structural transition is indicative of the structural flexibility of BSA as the 3 main domains are loosely linked up. 
This feature of structural transition is very different from that of $\mathrm{mAb}$ and its segments. On the other hand, NR revealed that surface adsorption of lactoferrin caused structural unfolding from the exposure of the protein molecules to the unsymmetrical energetic stretching across the interface forming two distinct regions, with a top dense layer of 15-20 $\AA$ on the air side and a bottom diffuse layer of some $50 \AA$ into the aqueous subphase. In contrast, small angle neutron scattering revealed that lactoferrin held its dimeric globular framework in aqueous solution, with the distance between the centers of the dimer varying in response to the ionic strength. ${ }^{30}$

The $\mathrm{pH}$-dependent thickness changes were also assessed and similar results were obtained for $\mathrm{Fc}$, Fab and $\mathrm{mAb}$, suggesting that $\mathrm{pH}$ variation did not cause measurable differences within the conditions studied. As shown from Figure 6B, increase in $\mathrm{pH}$ from 5.5 to 7 led to little change in their adsorption. Further $\mathrm{pH}$ increase from 8 to 8.8 led to modest decline in $\mathrm{Fc}$ adsorption but Fab adsorption showed a clear rise. The adsorption of mAb was dominated by the Fabs, modulated by Fc, resulting in a slight increase. Figure S1 depicts how the net charge on each fragment varies with increasing $\mathrm{pH}$. Fc bears the lowest net charge over the $\mathrm{pH}$ range studied and this may explain why it adsorbs most on the molar basis as shown in Figure 6B. In contrast, Fab has the highest net charge and this fits to its persistent lowest adsorption. The mAb adopts an intermediate position, also consistent with its net charge distribution across the $\mathrm{pH}$ range studied. An absence of thickness change indicates that the structural conformations adopted by Fc, Fab and mAb molecules on the surface of water did not alter whilst their surface charges varied, implying their robustness against $\mathrm{pH}$. In contrast to the $\mathrm{pH}$-dependent changes as observed from surface adsorption of lysozyme and BSA, ${ }^{28,29}$ the relative changes in adsorbed amount and layer thickness from mAb and its segments are small in spite of the large decrease in their net charges with rising $\mathrm{pH}$ (Figure S1).

As already outlined, the reflectivity profiles measured from NRW reveal the area per molecule $\left(A_{p}\right)$ and layer thickness from which the globular state and layer packing can be inferred. As shown in Table 2, $A_{p}$ can be estimated from the uniform layer modelling, giving $5100 \AA^{2}$ for Fc against its limiting value of $4600 \AA^{2}$, and $6800 \AA^{2}$ for Fab against its limiting value of $4000 \AA^{2}$ as shown from the projections in Figure S2 and S3. The differences between them reveal the greater extent of layer packing from $\mathrm{Fc}$ due to its greater surface activity. Note that this only reflected the extent of layer packing at $50 \mathrm{ppm}$. In contrast, $A_{p}$ was found to be about $12000 \AA^{2}$ for the mAb and is the same as the limiting area estimated from the lateral packing of $1 \mathrm{Fc}$ and $2 \mathrm{Fabs}$, assuming that each adopts its own limiting area as described above. This reveals a closer packing for the mAb layer compared to its 
constituent Fc and Fab layers whilst also taking into account the projection as schematically shown in Figure S4.

The surface adsorbed layers of Fc, Fab and mAb can be fully immersed, fully afloat or somewhere intermediate. Parallel measurements in solvents with non-zero contrasts could be informative of the extent of immersion of the layer in water. As mentioned earlier, the exact isotopic contrast of the water as solvent can be changed by varying the ratio of $\mathrm{H}_{2} \mathrm{O}$ and $\mathrm{D}_{2} \mathrm{O}$. When contrast matched to $2.58 \times 10^{-6} \AA^{-2}$ (CM2.58), the SLD of water exactly matched that of the mAb. Thus, only the mAb region that stays out of water is visible and the remaining region immersed in water is undistinguishable. The reflectivity measured from CM2.58 thus determines the thickness of the region above water. When measured from $\mathrm{D}_{2} \mathrm{O}$, both regions are visible but the total layer thickness and volume fraction must remain the same as measured from NRW. Changes in the ratio of $\mathrm{H}_{2} \mathrm{O}$ and $\mathrm{D}_{2} \mathrm{O}$ strongly influence the shape of the reflectivity profiles, as exemplified in Figure 8 from the adsorption of $50 \mathrm{ppm} \mathrm{Fc}$ and Fab under the 3 water contrasts. The large differences offer us confidence in revealing the extent of layer immersion in water through simultaneous model fitting.

In $\mathrm{D}_{2} \mathrm{O}$, the immersed part of a protein layer must be fitted by taking into account the contribution from the solvent for space filling as well, with the total of protein volume fraction $\left(\varphi_{p}\right)$ and solvent volume fraction $\left(\varphi_{w}\right)$ being equal to unity. The SLD contributions are related to the interfacial composition via the following equation: ${ }^{31,32}$

$$
\rho_{2}=\rho_{p} \varphi_{p}+\rho_{w} \varphi_{w}
$$

By undertaking simultaneous fitting to the reflectivity profiles measured under NRW, $\mathrm{CM} 2.58$ and $\mathrm{D}_{2} \mathrm{O}$, we can not only determine the extent of protein layer immersion into water but also confirm the total protein layer thickness and volume fraction as obtained from NRW alone previously.

Figure 8 shows the best fits to the 3 sets of the 3 reflectivity profiles measured at $50 \mathrm{ppm}$ and pH 5.5 for Fab, Fc and mAb, with the matching structural parameters listed in Table 2. All 3 reflectivity profiles measured in $\mathrm{CM} 2.58$ could be fitted to $15 \pm 2 \AA$, implying partial immersion into water. In the case of $\mathrm{Fc}$ adsorption, the $\mathrm{D}_{2} \mathrm{O}$ profile could be fitted to an upper layer of $15 \pm 2 \AA$ in air and a lower layer of $25 \pm 2 \AA$ in water and the total thickness of $40 \pm 2 \AA$, consistent with the value obtained from the fitting to the NRW profile. In addition, the volume fraction of the $\mathrm{Fc}$ in $\mathrm{CM} 2.58$ and $\mathrm{D}_{2} \mathrm{O}$ was kept the same within experimental errors. Therefore, the only parameters that varied were the upper and lower layer thicknesses and the matching SLDs, with the total thickness and volume fraction kept the same as those 
obtained from the fitting to the NRW profile. For the adsorption of Fab, the thickness of the lower layer was fitted into $40 \pm 2 \AA$ and this together with the upper layer of $10 \pm 2 \AA$ makes the total of $50 \pm 2 \AA$, also consistent with that from the fitting of the NRW profile. In contrast, the best fitting to the 3 reflectivity profiles measured for $\mathrm{mAb}$ produced similar structural parameters as obtained from Fab adsorption, suggesting an inter-domain flexibility during surface adsorption.

The outcome of the data analysis is also shown as schematic drawings in Figure 8, where it can be seen that both Fc and Fab fragments are partially immersed. The total Fc layer is thinner than that of the Fab layer, but the mAb layer is maintained under similar thickness to that of the Fab layer, showing that all the fragments are also packed in parallel in the mAb layer. As also evident from Table 2, the Fc shows preferable adsorption out of the surface of water because of its relatively more hydrophobic nature.

Both lysozyme and BSA layers were found to have the portion of some 10-15 $\AA$ exposed to air, with the exact extent being dependent on solution conditions. Thus, this feature of 10-15 $\AA$ of the top region being exposed to air seems to be rather common for the adsorbed protein layers. This feature is also evident from Table 2 for all adsorbed layers studied here; as the Fc is less charged and more hydrophobic its top layer of $15 \AA$ in air occupies a greater fraction, although this effect does not appear in the mAb layer.

The concentration range of $\mathrm{Fab}, \mathrm{Fc}$ and $\mathrm{mAb}$ studied in this work was relatively low due to the limited amount of samples available. However, the nature of surface adsorption of proteins is such that they tend to reach saturation at rather low bulk concentrations. As evident from Table 2, the average volume fraction of mAb or its fragments packed in the layer at $50 \mathrm{ppm}$ reached some 0.3. At such a high packing density, it is likely that physical interactions occur within the adsorbed layer, causing structural deformation or entanglement, with different implications on their ability to desorb. This is an aspect that will be pursued in future work.

These results present some biopharmaceutical considerations: i) modelling the net surface charge during the design and engineering of a mAb candidate provides information that can be correlated to adsorption behavior; ii) alteration of the formulation buffer $\mathrm{pH}$, particularly over the mildly acidic range commonly used for mAbs, does not have significant impact on adsorption behavior; iii) adsorption at relatively high surface packing densities is not necessarily associated with extensive conformational unfolding, though the effect of packing on desorption needs further investigation; iv) high surface packing densities exist even at low 
bulk concentrations and may impact the dose administered via a giving set containing very low mAb concentrations.
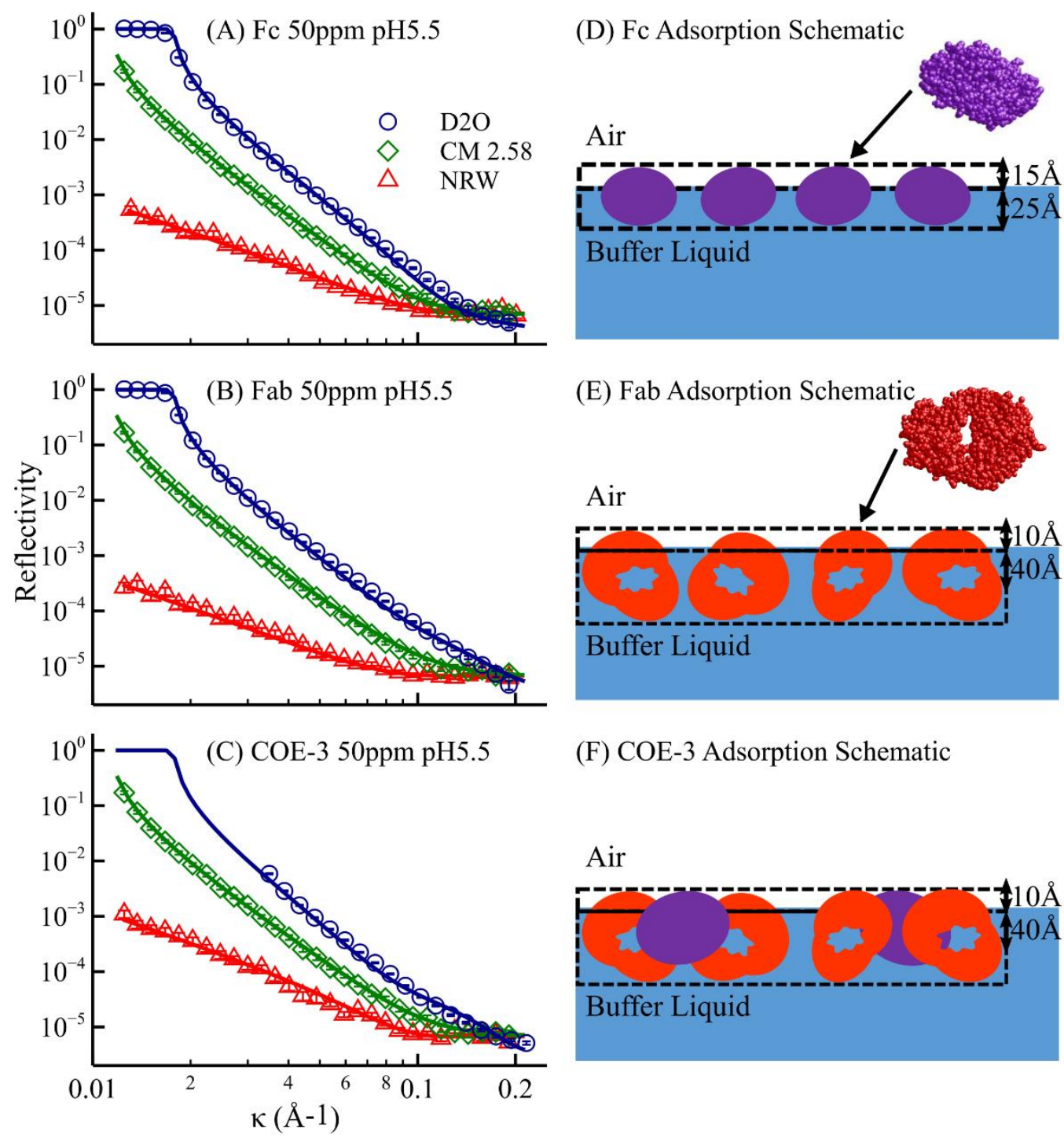

(F) COE-3 Adsorption Schematic

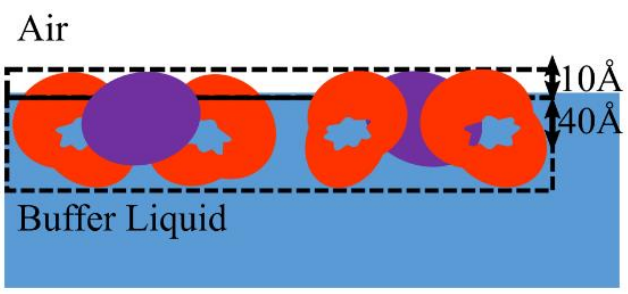

Figure 8. Neutron reflectivity profiles (left) measured at $50 \mathrm{ppm}$ of $F c(A), F a b(B)$ and $m A b$ $(\mathrm{COE}-3, \mathrm{C})$ on the surface of water under $\mathrm{NRW}, \mathrm{CM} 2.58$ and $\mathrm{D}_{2} \mathrm{O}$ at $\mathrm{pH} 5.5$ (His buffer, ionic strength $=25 \mathrm{mM}$ ) and schematic representations (right) of the surface adsorbed $\mathrm{Fc}$ $(D), F a b(E)$ and $m A b(F)$ layers.

Table 2. Structural parameters obtained from the best fits to NR profiles measured under 3 solvent contrasts from adsorption of Fab, $\mathrm{Fc}$ and $\mathrm{mAb}(\mathrm{COE}-3)$ at $50 \mathrm{ppm}$ and $\mathrm{pH} 5.5$

\begin{tabular}{|c|c|c|c|c|c|c|}
\hline Sample & Contrast & $\begin{array}{l}\text { Thickness } \\
\text { /Å }\end{array}$ & SLD $\times 10^{6} / \AA^{-2}$ & $\begin{array}{c}\text { Volume } \\
\text { fraction }\end{array}$ & $\begin{array}{c}\text { Area per } \\
\text { molecule/ } \AA^{2}\end{array}$ & $\begin{array}{c}\text { Adsorbed } \\
\text { amount } / \mathrm{mgm}^{-2}\end{array}$ \\
\hline $\begin{array}{c}\mathrm{Fc} \text { at 50ppm, } \\
\mathrm{pH} \mathrm{5.5}\end{array}$ & NRW & 40 & 0.583 & 0.29 & 5100 & 1.61 \\
\hline & CM 2.58 & 15 & 0.79 & 0.31 & & 0.64 \\
\hline & $\mathrm{D}_{2} \mathrm{O}$ layer $1 / 2$ & $15 / 25$ & $1 / 5.47$ & $0.31 / 0.27$ & & $0.65 / 0.96$ \\
\hline $\begin{array}{c}\text { Fab at } \\
50 \mathrm{ppm}, \mathrm{pH} \\
5.5\end{array}$ & NRW & 50 & 0.340 & 0.16 & 6800 & 1.16 \\
\hline
\end{tabular}




\begin{tabular}{|l|c|c|c|c|c|c|}
\hline & $\mathrm{CM} 2.58$ & 10 & 0.415 & 0.16 & & 0.23 \\
\hline & $\mathrm{D}_{2} \mathrm{O}$ layer1/2 & $10 / 40$ & $0.55 / 5.83$ & $0.16 / 0.16$ & & $0.23 / 0.93$ \\
\hline $\begin{array}{l}\text { COE-3 at } \\
\text { 50ppm, pH }\end{array}$ & & & & & 12000 & \\
\hline & $\mathrm{NRW}$ & 50 & 0.59 & 0.29 & & 2.01 \\
\hline & $\mathrm{CM} 2.58$ & 10 & 0.85 & 0.33 & & 0.46 \\
\hline & $\mathrm{D}_{2} \mathrm{O}$ layer1/2 & $10 / 40$ & $1.1 / 5.5$ & $0.33 / 0.27$ & & $0.46 / 1.55$ \\
\hline
\end{tabular}

\section{Conclusions}

NR has been used in this work to study the surface adsorption of a mAb and its constituent Fab and Fc through parallel studies under different water contrasts to help highlight interfacial structural resolution. The results have revealed that $\mathrm{Fc}$ adsorbed fastest and the dynamic process tended to equilibrate over the first $1 \mathrm{hr}$, with the highest adsorbed amount in $\mathrm{nmol} / \mathrm{m}^{2}$ observed. In contrast, Fab adsorbed slowest and the dynamic process was concentration-dependent with the lower concentration showing the longer equilibration time. Its adsorbed amount in $\mathrm{nmol} / \mathrm{m}^{2}$ was the lowest. The dynamic process and the adsorbed amount of the mAb were dominated by the two Fabs, with evident influence from Fc. The different behavior appears to be well correlated to the net charges they bear: Fc carries a much lower net surface charge than Fab and is thus far more surface active. As the bulk concentration increased, Fc layers remained at about $40 \AA$; Fab and mAb layers were about 45-50 ̊ thick, showing that all adsorbed layers adopted the conformations with their short axial dimensions perpendicular to the water surface. The slight thickness increase in the case of $\mathrm{Fab}$ and $\mathrm{mAb}$ was indicative of conformational adjustment with increasing concentration. The net charge on $\mathrm{Fab}, \mathrm{Fc}$ and $\mathrm{mAb}$ varied as $\mathrm{pH}$ increased from 5.5 to 8.8, but these charge differences did not appear to cause any major changes in adsorbed amount, although there was a small and opposite trend of adsorption between $\mathrm{Fab}$ and $\mathrm{Fc}$ from $\mathrm{pH} 8$ to 8.8. The layer thicknesses remained little changed, showing that $\mathrm{mAb}$ and its constituent fragments remained globular and held similar conformations, even though they carried different charges. Although the concentration range studies were low, the average surface volume fraction from the adsorbed layer at $50 \mathrm{ppm}$ reached 0.3 , which is quite high for protein systems. Under such a high surface packing density, molecules can easily become deformed and entangled. Future work will examine how desorption is affected by different surface packing density.

\section{Supporting Information}


The Supporting Information including sequences for the light and heavy chains of the mAb studied here and comparisons against the one with crystalline structures of its fragments is available free of charge on the ACS Publications webpage.

\section{Acknowledgements}

We thank funding support from MedImmune Ltd, neutron beam times awarded to undertake this work at ISIS Neutron Facility, Chilton, Didcot, under the support of STFC. ZL acknowledges studentship support from University of Manchester via an Overseas Research Scholarship (ORS) award and a physics research merit award. CS acknowledges a joint PhD studentship from STFC, Unilever and University of Manchester.

\section{References}

[1] Monoclonal Antibodies: Development, Delivery and Applications. Lei Zheng \& Mohammed Shameem, John Hopkins School of Medicine, USA \& Merck, USA. Pub: Future Science Ltd., November 2015, doi: 10.4155/9781910419472.

[2] Jefferis, R.; Lund, J.; Mizutani, H.; Nakagawa, H.; Kawazoe, Y.; Arata, Y.; Takahashi, N.. A Comparative Study of the N-linked Oligosaccharide Structures of Human IgG Subclass Proteins. Biochem J. 1990, 268, 529-537. PMCID: PMC1131471

[3] Jiang, Q.; Chiew, Y.C. Dynamics of Adsorption and Desorption of Proteins at an AirWater Interface. Colloids Surf B Biointerfaces 2001, 20, 303-308.

[4] Majumdar, R.; Esfandiary, R.; Bishop, S.M.; Samra, H.S.; Middaugh, C.R.; Volkin, D.B.; Weis, D.D. Correlations between Changes in Conformational Dynamics and Physical Stability in a Mutant IgG1 mAb Engineered for Extended Serum Half-life. J. Pharm. Sci. 2014, 103, 437-444. doi: 10.1002/jps.23822.

[5] Castellanos, M.M.; Pathak, J.A.; Colby, R.H. Both Protein Adsorption and Aggregation Contribute to Shear Yielding and Viscosity Increase in Protein Solutions. Soft Matter 2014, $10(1), 122-131$.

[6] Shieh, I.C.; Patel, A.R. Predicting the Agitation-Induced Aggregation of Monoclonal Antibodies Using Surface Tensiometry. Mol Pharmaceut 2015, 12(9), 3184-3193.

[7] Oom, A.; Poggi, M.; Wikstrom, J.; Sukumar, M. Surface Interactions of Monoclonal Antibodies Characterized by Quartz Crystal Microbalance with Dissipation: Impact of Hydrophobicity and Protein Self-interactions. J Pharm Sci-US 2012, 101(2), 519-529.

[8] Hartl, E.; Dixit, N.; Besheer, A.; Kalonia, D.; Winter, G. Weak Antibody-Cyclodextrin Interactions Determined by Quartz Crystal Microbalance and Dynamic/Static Light Scattering. Eur J Pharm Biopharm 2013, 85(3), 781-789.

[9] Kapp, S.J.; Larsson, I.; Van De Weert, M.; Cardenas, M.; Jorgensen, L. Competitive Adsorption of Monoclonal Antibodies and Nonionic Surfactants at Solid Hydrophobic Surfaces. J Pharm Sci-US 2015, 104(2), 593-601.

[10] Hoehne, M.; Samuel, F.; Dong, A.; Wurth, C.; Mahler, H.C.; Carpenter, J.F.; Randolph, T.W.. Adsorption of Monoclonal Antibodies to Glass Microparticles. J Pharm Sci-US 2011, 100(1), 123-132. 
[11] Leiske, D.L.; Shieh, I.C.; Tse, M.L.. A Method to Measure Protein Unfolding at an AirLiquid Interface. Langmuir 2016, 32(39), 9930-9937.

[12] Perevozchikova, T.; Nanda, H.; Nesta, D.P.; Roberts, C.J. Protein Adsorption, Desorption, and Aggregation Mediated by Solid-Liquid Interfaces. J Pharm Sci-US 2015, 104(6), 1946-1959.

[13] Gerhardt, A.; Mcumber, A.C.; Nguyen, B.H.; Lewus, R.; Schwartz, D.K.; Carpenter, J.F.; Randolph, T.W. Surfactant Effects on Particle Generation in Antibody Formulations in Pre-filled Syringes. J Pharm Sci-US 2015, 104(12), 4056-4064.

[14] Lakey, J.H. Neutrons for Biologists: a Beginner's Guide, or Why You Should Consider Using Neutrons. J. Roy. Soc. Interface 2009, 6, S567-S573.

[15] McIntosh, L.; Whitelaw, C.; Rekas, A.; Holt, S.A.; van der Walle, C.F. Interrogating Protonated/Deuterated Fibronectin Fragment Layers Adsorbed to Titania by Neutron Reflectivity and Their Concomitant Control over Cell Adhesion. J. Roy. Soc. Interface 2015, 12(107). 20150164. DOI: 10.1098/rsif.2015.0164

[16] Tucker, I.M.; Petkov, J.T.; Penfold, J.; Thomas, R.K.; Cox, A.R.; Hedges, N. Adsorption of Hydrophobin/beta-casein Mixtures at the Solid-Liquid Interface. J Colloid Interf Sci 2016, 478, 81-87.

[17] Smith, C.; Li, Z.; Holman, R.; Pan, F.; Campbell, R.A.; Campana, M.; Li, P.; Webster, J.R.P.; Bishop, S.; Narwal, R.; Uddin, S.; van der Walle, C.F.; Lu, J.R. Antibody Adsorption on the Surface of Water Studied by Neutron Reflection. Mabs 2017,9(3), 466-475.

[18] Roberts, D.; Keeling, R.; Tracka, M.; van der Walle, C.F.; Uddin, S.; Warwicker, J.; Curtis, R. The Role of Electrostatics in Protein-Protein Interactions of a Monoclonal Antibody. Molecular Pharmaceutics 2014, 11 (7), 2475-2489.

[19] Lu, J.R.; Lee, E.M.; Thomas, R.K. The Analysis and Interpretation of Neutron and X-ray Specular Reflection. Acta Crystallographica Section A 1996, 52(1), 11-41.

[20] Saphire, E.O.; Parren, P.W.; Pantophlet, R.; Zwick, M.B.; Morris, G.M.; Rudd, P.M.; Dwek, R.A.; Stanfield, R.L.; Burton, D.R.; Wilson, I.A. Crystal Structure of a Neutralizing Human IGG against HIV-1: a Template for Vaccine Design. Science 2001, 293(5532), 11551159.

[21] Krapp, S.; Mimura, Y.; Jefferis, R.; Huber, R.; Sondermann, P. Structural Analysis of Human IgG-Fc Glycoforms Reveals a Correlation between Glycosylation and Structural Integrity. J. Mol. Biol. 2003, 325(5), 979-989.

[22] Tamada, T.; Shinmi, D.; Ikeda, M.; Yonezawa, Y.; Kataoka, S.; Kuroki, R.; Mori, E.; Motoki, K. TRAIL-R2 Superoligomerization Induced by Human Monoclonal Agonistic Antibody KMTR2. Sci. Rep. 2015, 5, 17936.

[23] Couston, R.G.; Skoda, M.W.; Uddin, S.; van der Walle, C.F. Adsorption Behavior of a Human Monoclonal Antibody at Hydrophilic and Hydrophobic Surfaces. Mabs 2013, 5(1), 126-139.

[24] Lu, J.R.; Thomas, R.K. Neutron Reflection from Wet Interfaces. J. Chem. Soc. Faraday Trans. 1998, 94(8), 995-1018.

[25] Lu, J.R.; Thomas, R.K.; Penfold, J. Surfactant Layers at the Air/Water Interface: Structure and Composition. Adv. Colloid Interface Sci. 2000, 84(1-3), 143-304.

[26] Nelson, A. Co-refinement of Multiple-Contrast Neutron/X-ray Reflectivity Data Using MOTOFIT. J. Applied Crystallography 2006, 39(2), 273-276.

[27] Born, M.; Wolf, E. Principles of Optics; Electromagnetic Theory of Propagation, Interference and Diffraction of Light. 4th ed., Pergamon Press, Oxford, New York,, 1969.

[28] Lu, J.R.; Su, T.J.; Thomas, R.K.; Penfold, J.; Webster, J.R.P. Structural Conformation of Lysozyme Layers at the Air/Water Interface Studied by Neutron Reflection. J. Chem. Soc. Faraday Trans. 1998, 94(21), 3279-3287. 
[29] Lu, J.R.; Su, T.J.; Thomas, R.K. Structural Conformation of Bovine Serum Albumin Layers at the Air-Water Interface Studied by Neutron Reflection. J. Colloid Interface Sci. 1999, 213(2), 426-437.

[30] Lu, J.R.; Perumal, S.; Zhao, X.B.; Miano, F.; Enea, V.; Heenan, R.R.; Penfold, J. Surface-Induced Unfolding of Human Lactoferrin. Langmuir 2005, 21(8), 3354-3361.

[31] Green, R.J.; Su, T.J.; Joy, H.; Lu, J.R. Interaction of Lysozyme and Sodium Dodecyl Sulfate at the Air-Liquid Interface. Langmuir 2000, 16(13), 5797-5805.

[32] Lu, J.R.; Su, T.J.; Thomas, R.K. Binding of Surfactants onto Preadsorbed Layers of Bovine Serum Albumin at the Silica-Water Interface. J. Phys. Chem. B 1998, 102(50), 10307-10315. 


\section{Support Information}

\section{Neutron reflection study of surface adsorption of Fc, Fab and the whole}

mAb

Zongyi Li [1], Ruiheng Li [1], Charles Smith [1], Fang Pan [1], Mario Campana [2], John R P Webster [2], Christopher F van der Walle [3], Shahid Uddin [3], Steve M Bishop [4],

Rojaramani Narwal [4], Jim Warwicker [5], Jian Ren Lu* [1]

[1] Biological Physics Laboratory, School of Physics and Astronomy, University of Manchester, Oxford Road, Schuster Building, Manchester M13 9PL, UK.

[2] ISIS Neutron Facility, STFC, Chilton, Didcot OX11 0QZ, UK.

[3] Formulation Sciences, MedImmune Ltd, Sir Aaron Klug Building, Granta Park, Cambridge CB21 6GH, UK

[4] Formulation Sciences, MedImmune LLC, Gaithersburg, MD 20878, USA.

[5] Manchester Institute of Biotechnology, School of Chemistry, University of Manchester, 131 Princess Street, Manchester M1 7DN, UK.

*Corresponding author: Jian R Lu (email: j.lu@ manchester.ac.uk; tel: +44 161 2003926) 
Table S1. The antibody molecule is comprised of 2 identical light and heavy polypeptide chains.

The non-modified sequence of the Light Chain:

DIQMTQSPSSLSASVGDRVTITCRASQSISSYLNWYQQKPGKAPKLLIYAASSLQSGV PSRFSGSGSGTDFTLTISSLQPEDFATYYCQQSYSTPLTFGGGSKVEIKRTVAAPSVFIF PPSDEQLKSGTASVVCLLNNFYPREAKVQWKVDNALQSGNSQESVTEQDSKDSTYS LSSTLTLSKADYEKHKVYACEVTHQGLSSPVTKSFNRGEC

The non-modified sequence of the Heavy Chain:

QVNLRESGGGLVQPGGSLRLSCAASGFTFGSYAMSWVRQAPGKGLEWVSAISGSGG STYYADSVKGRFTISRDNSKNSLYLQMNSLRAEDTAVYYCARRSIYGGNYYFDYWG RGTLVTVSSASTKGPSVFPLAPSSKSTSGGTAALGCLVKDYFPEPVTVSWNSGALTSG VHTFPAVLQSSGLYSLSSVVTVPSSSLGTQTYICNVNHKPSNTKVDKKVEPKSCDKT HTCPPCPAPELLGGPSVFLFPPKPKDTLMISRTPEVTCVVVDVSHEDPEVKFNWYVD GVEVHNAKTKPREEQYNSTYRVVSVLTVLHQDWLNGKEYKCKVSNKALPAPIEKTI SKAKGQPREPQVYTLPPSRDELTKNQVSLTCLVKGFYPSDIAVEWESNGQPENNYKT TPPVLDSDGSFFLYSKLTVDKSRWQQGNVFSCSVMHEALHNHYTQKSLSLSPGK

The sequences were entered into the Biomolecular Scattering Length Density Calculator (http://psldc.isis.rl.ac.uk/Psldc/) and the influence of the isotopic contrast of water was set accordingly to obtain the respective scattering lengths (SL) and scattering length density (SLD) under NRW, CM 2.58 and $\mathrm{D}_{2} \mathrm{O}$, with the results shown in Table 1.

Following papain digest, each non-modified Fab will be composed of the Heavy Chain sequence in red text and the whole of the Light Chain; each non-modified Fc will be composed of the Heavy Chain sequence in blue, existing as a dimer. The N-glycan at Asn (underlined) is predominantly G0f (For more details on sugar side chains, see Jefferis, R.; Lund, J.; Mizutani, H.; Nakagawa, H.; Kawazoe, Y.; Arata, Y.; Takahashi, N.. A Comparative Study of the N-linked Oligosaccharide Structures of Human IgG Subclass Proteins. Biochem J. 1990, 268, 529-537).

Table S2. Key parameters used for $\mathrm{H}_{2} \mathrm{O}$ and $\mathrm{D}_{2} \mathrm{O}$

\begin{tabular}{|l|l|l|l|}
\hline Molecular structure & SL $\times 10^{5} / \AA$ & ${\text { Volume } / \AA^{3}}^{3}$ & SLD $\times 10^{6} / \AA^{-2}$ \\
\hline $\mathrm{H}_{2} \mathrm{O}$ & -1.68 & 30 & -0.56 \\
\hline $\mathrm{D}_{2} \mathrm{O}$ & 19.14 & 30 & 6.35 \\
\hline
\end{tabular}


Tables S3. Amino acid sequence comparison between Fc of COE-03 and Fc of $1 \mathrm{HZH}$.

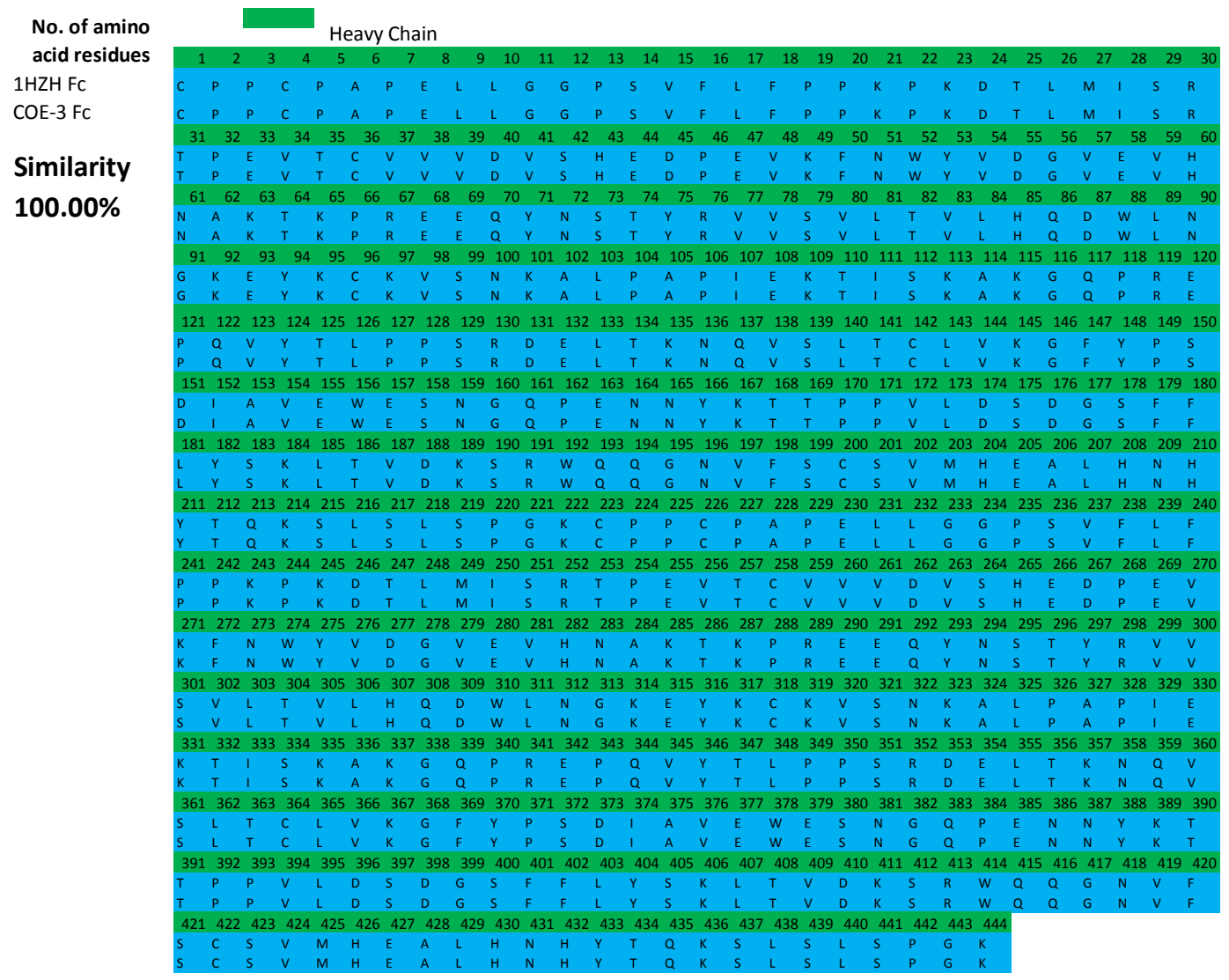

The 1HZH Fc sequence was from E.O. Saphire, P.W. Parren, R. Pantophlet, M.B. Zwick, G.M. Morris, P.M. Rudd, R.A. Dwek, R.L. Stanfield, D.R. Burton, I.A. Wilson, Crystal structure of a neutralizing human IGG against HIV-1: a template for vaccine design, Science 2001, 293(5532), 1155-1159. 
Table S4. Amino acid sequence comparison between Fab of COE-3 and Fab of 1HZH.

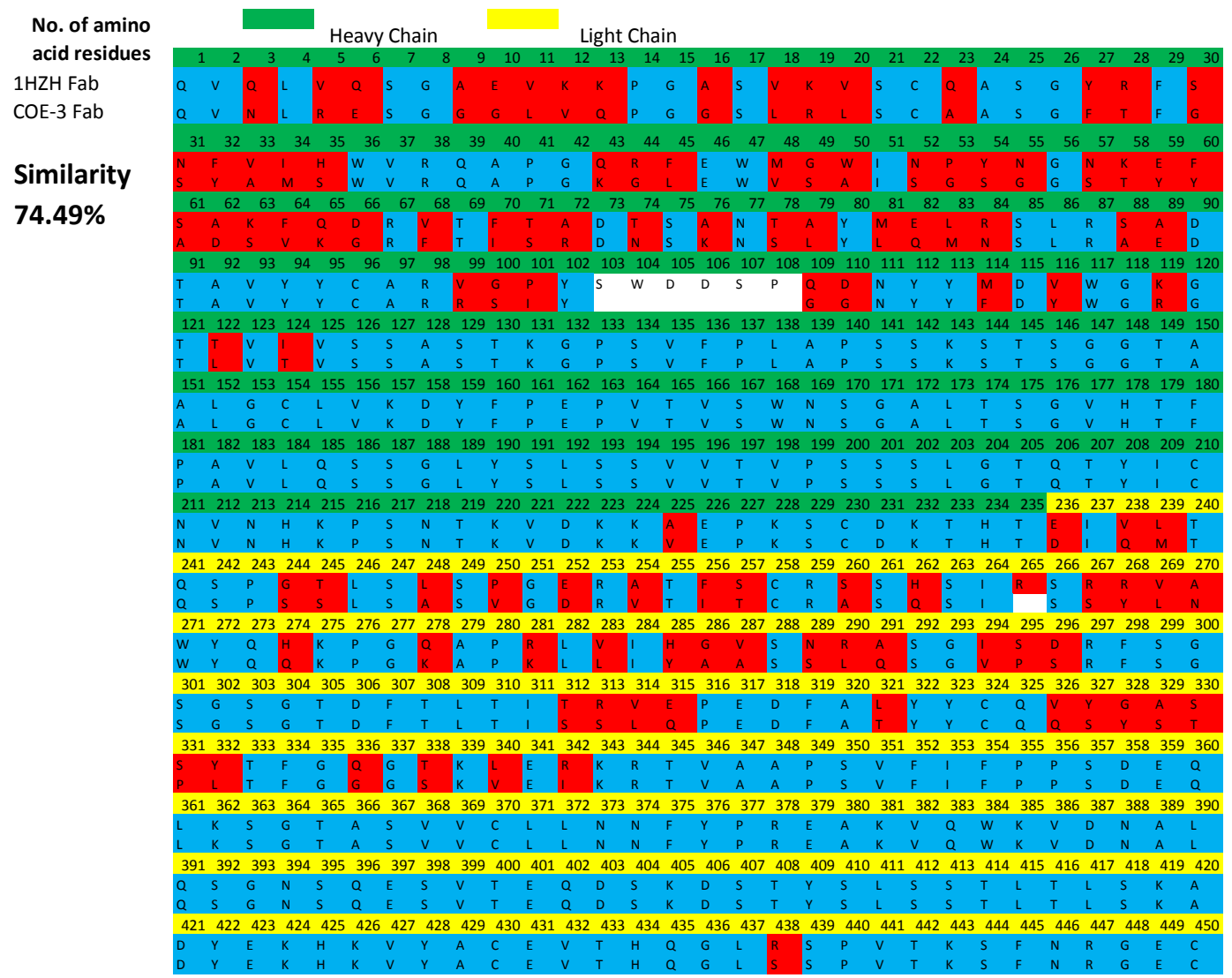

The 1HZH Fab sequence was from E.O. Saphire, P.W. Parren, R. Pantophlet, M.B. Zwick, G.M. Morris, P.M. Rudd, R.A. Dwek, R.L. Stanfield, D.R. Burton, I.A. Wilson, Crystal structure of a neutralizing human IGG against HIV-1: a template for vaccine design, Science 2001, 293(5532), 1155-1159. 
Figure $\mathrm{S} 1$. Charge distributions as a function of $\mathrm{pH}$ for $\mathrm{Fab}$ and $\mathrm{Fc}$ and one third of the whole COE-3 (1/3 contribution from $1 \mathrm{Fc}$ and 2 Fabs). These charge distributions were calculated with a Debye-Hückel model for $\mathrm{pKa}$ changes due to charge-charge interactions, applied at an ionic strength of $0.025 \mathrm{M}$ to $\mathrm{mAb}, \mathrm{Fc}$ and $\mathrm{Fab}$ models previously generated for $\mathrm{COE}-3$ (Roberts et al Mol. Pharm. 2014, 11, 2475).

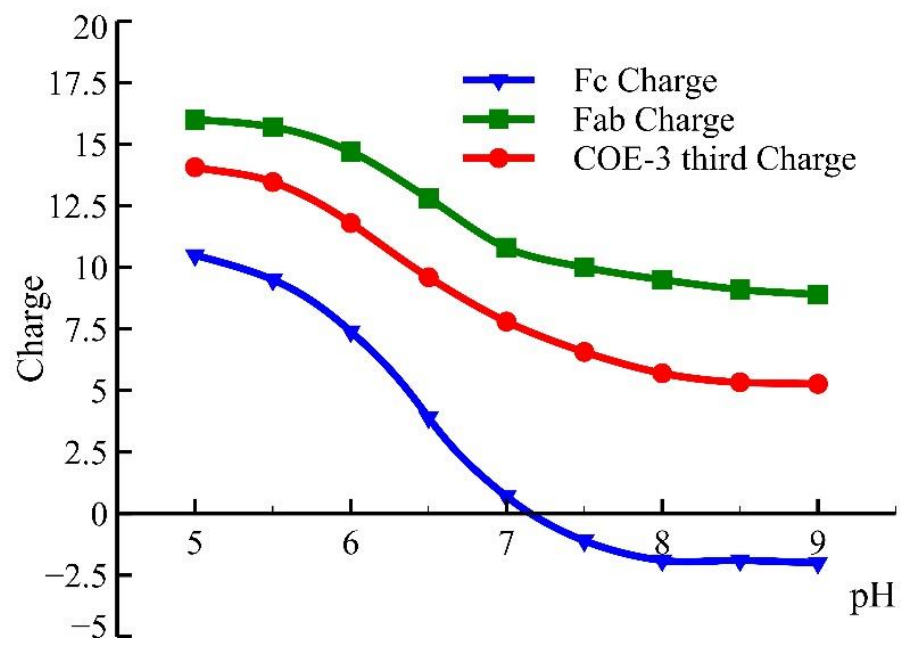

Note that these charge variations against $\mathrm{pH}$ as calculated from the constituent amino acids are different from the measured IP values from real experimental measurements due to the ignorance of charges on sugar groups and associations with ions from bulk solution. 
Fc of 1HZH:

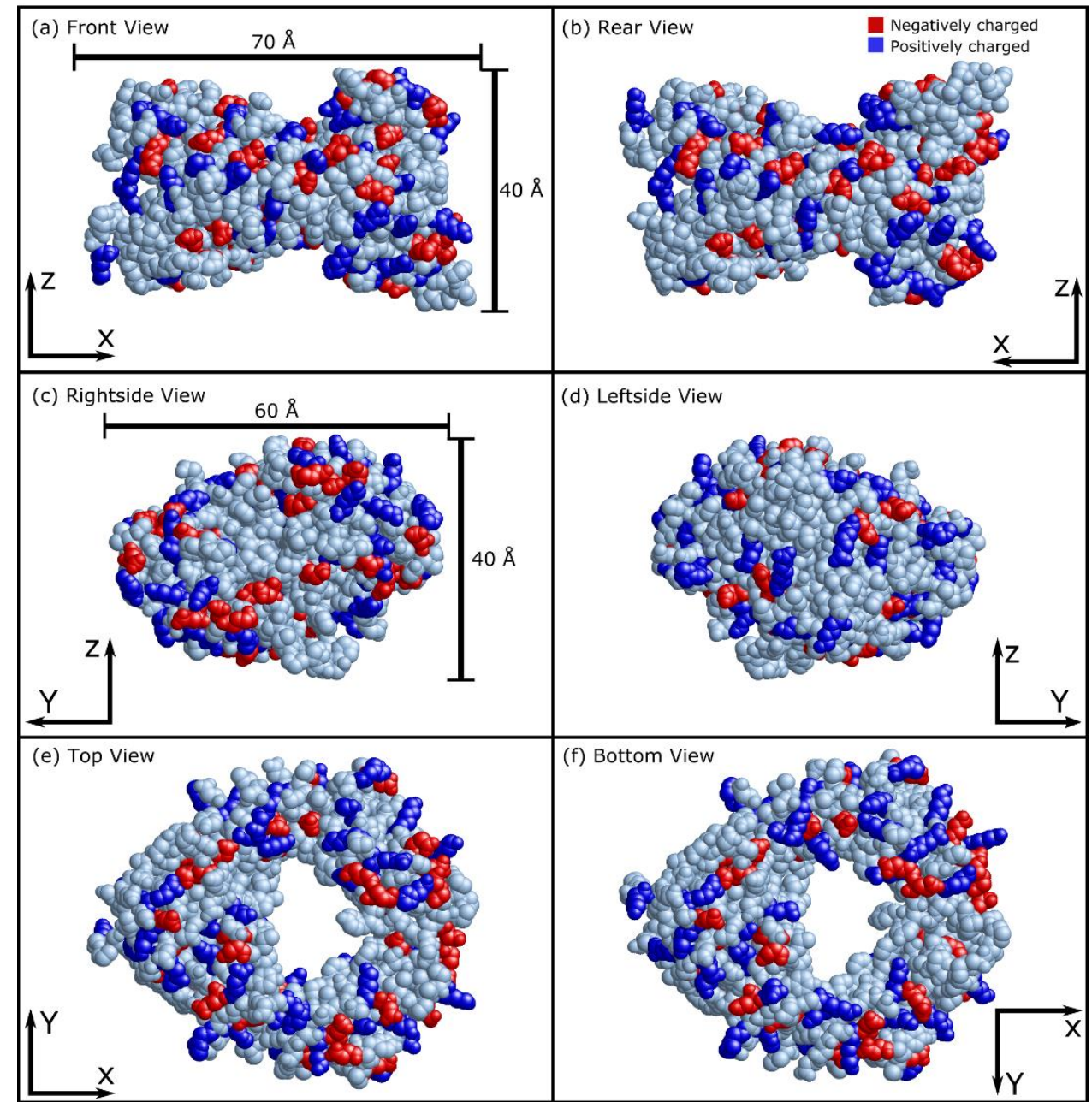

Figure S2. Projections of the 3D Fc crystalline structure with estimated width and height marked: (a) Front view; (b) Rear view; (c) Rightside view; (d) Leftside view; (e) Top view; (f) Bottom view. Blue color marks basic amino acid groups and red color marks acidic amino acid groups. 
Fab of $1 \mathrm{HZH}$ :

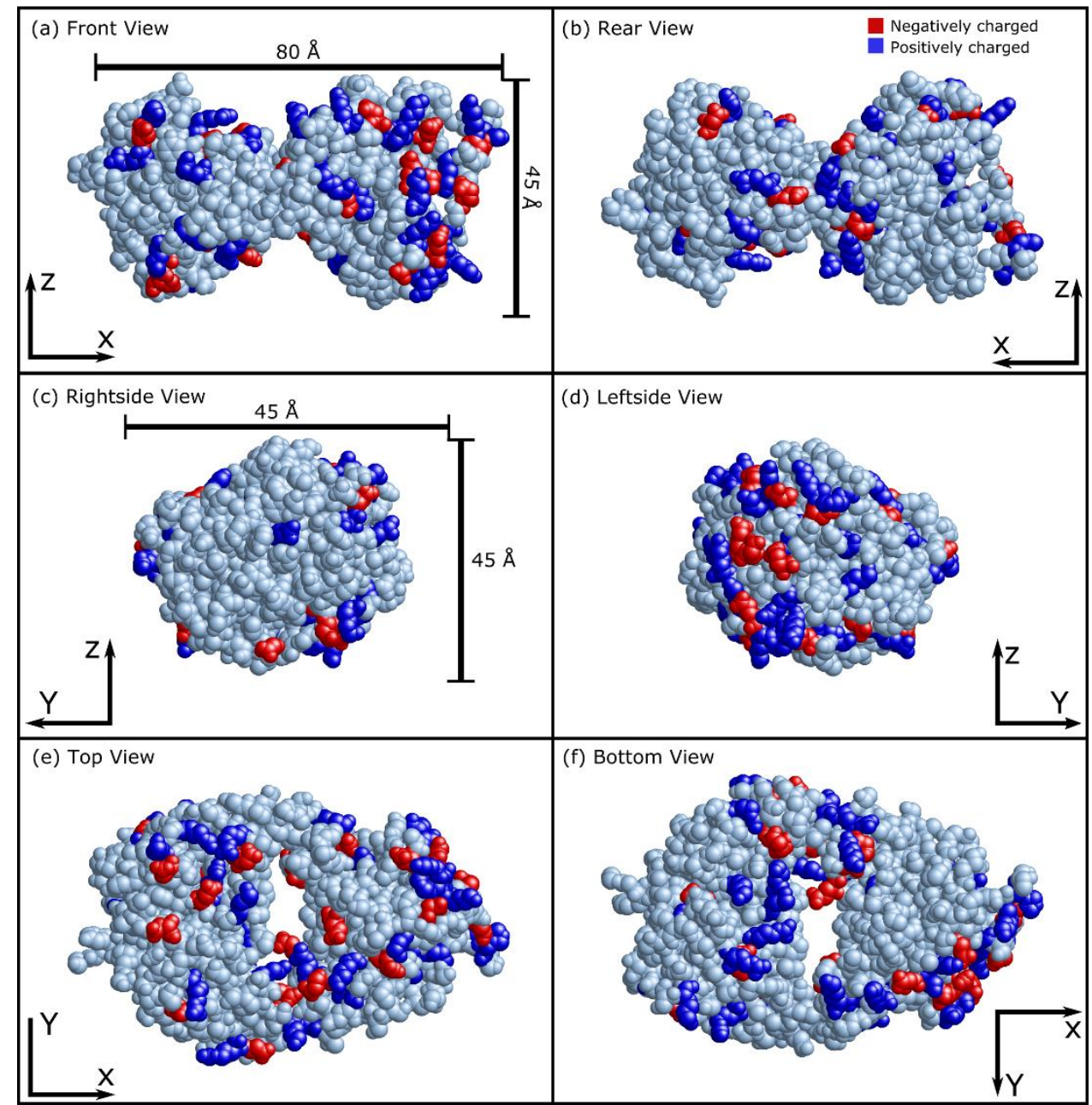

Figure S3. Projections of the 3D crystalline structure of Fab (1HZH) with estimated width and height marked: (a) Front view; (b) Rear view; (c) Rightside view; (d) Leftside view; (e) Top view; (f) Bottom view. Blue color marks basic amino acid groups and red color marks acidic amino acid groups. 


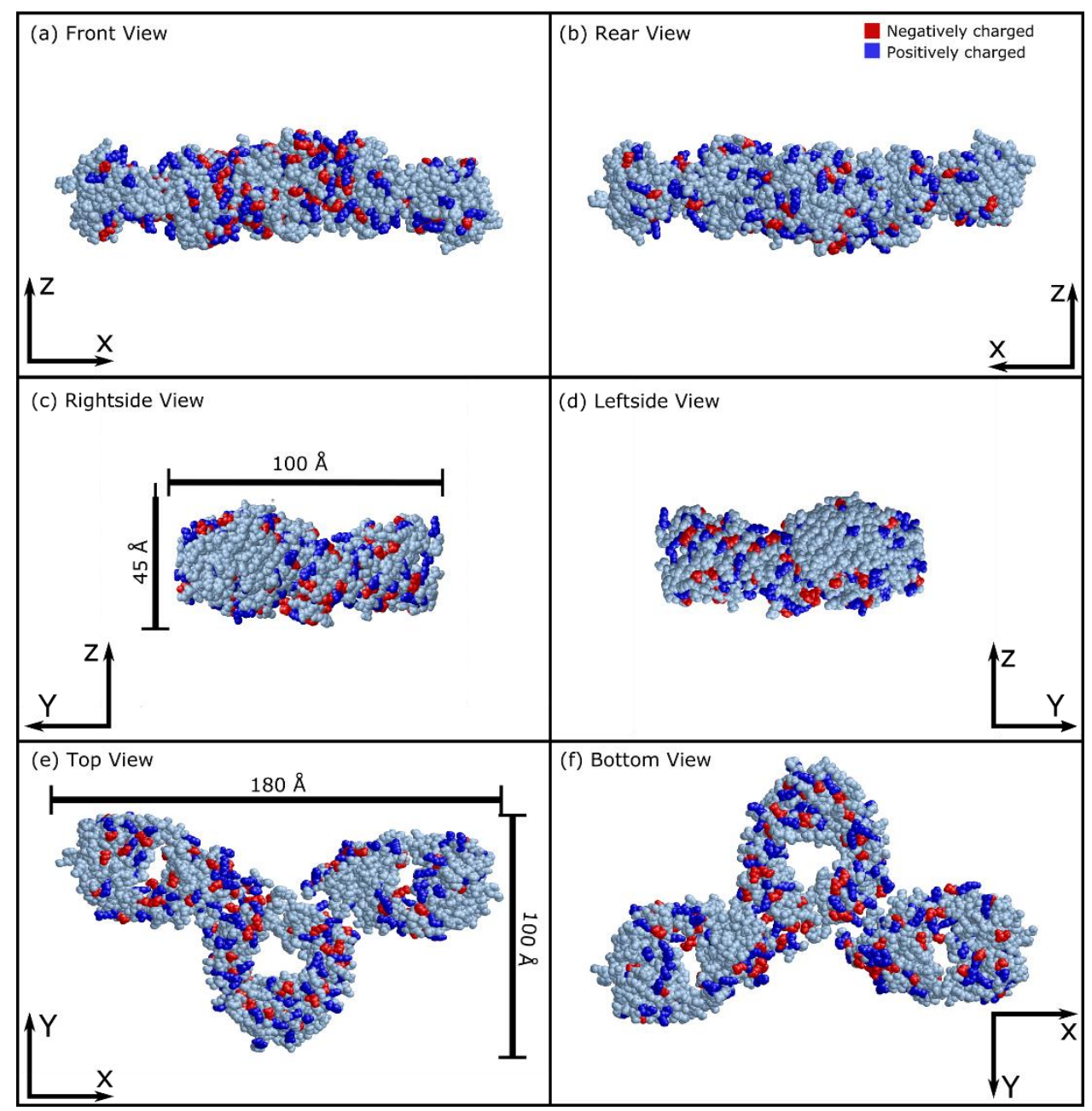

Figure S4. Projections of the 3D crystalline structure of the whole antibody1HZH with estimated width and height marked: (a) Front view; (b) Rear view; (c) Rightside view; (d) Leftside view; (e) Top view; (f) Bottom view. Blue color marks basic amino acid groups and red color marks acidic amino acid groups. 